\title{
Structural Evolution of Sol-Gel Glasses
}

\author{
George W. SCHERER \\ Experimental Station E 356/384, Central R \& D Dept., E. I. DuPont de Nemours \& Co.
Wilmington, DE 19898 , USA
}

\section{ゾル・ゲルガラスにおける構造の進化}

\author{
George W. Scherer \\ (イー・アイ・デュポン・ド・ヌムール・アンド・カンパニー)
}

\begin{abstract}
This review examines the stages of the sol-gel process, including hydrolysis, condensation, gelation, aging, drying, and sintering. The species produced in the sol are polymeric, rather than being dense glass-like colloidal particles. Considerable control over the structure of the polymer is possible through an understanding of the chemistry of hydrolysis and condensation. The properties of the gel and its response to heat treatment are sensitive to the structure created in the sol stage. Solvent must be removed slowly to prevent the high capillary stresses from causing cracking. A model of drying is presented that explains the relationship between cracking, drying rate, gel size, and permeability. Heat treatment causes densification of the solid phase, as well as collapse of the pores. The sintering behavior of gels is complex, because the viscosity of the gel is affected by concurrent structural relaxation and changes in hydroxyl content.

[Received October 14, 1986]
\end{abstract}

Key-words : Gel, Hydrolysis, Condensation, Gelation, Aging, Syneresis, Permeability, Drying, Sintering

\section{Introduction}

The term "sol-gel processing" is broadly used to describe the preparation of inorganic oxides by wet chemical methods. The precursor compounds may be inorganic salts or organometallic compounds ; colloidal dispersions of silica have often been incorporated. The first application of this technology was in the preparation of thin films $(<1$ micrometer $)$ of single oxides ${ }^{1,2)}$; later, techniques for making multicomponent materials were developed ${ }^{3}$. These chemical approaches were used to prepare batch for melting ${ }^{4)-6}$, because very homogeneous materials could be prepared with relative ease. Preparation of large pieces of gel was found to be difficult, because the gels cracked during drying. Shoup ${ }^{7)}$ showed that large bodies of silica gel could be prepared from alkali silicates, but the technique was limited to that material. Then it was demonstrated by Yoldas $^{8,9)}$, Yamane et al. ${ }^{10,11)}$, and Nogami and Moriya ${ }^{12)}$ that monolithic gels could be made by polymerization of organometallic compounds, and an explosion of activity began. The motivation for the research was the expectation that materials could be prepared at low temperatures that would be very pure and homogeneous. Moreover, it was hoped that new materials could be prepared that are too difficult to make by conventional methods, because they are refractory or prone to undesirable phase changes. Those goals have been met in a variety of systems. In addition to the practical advances, there is now a considerable body of scientific knowledge underlying the technology of sol-gel processing, and that is the subject of this review.

This area of research has been so active that it cannot be thoroughly reviewed in a single article. The present paper is therefore limited to the preparation of amorphous oxides from organometallic gels. It does not discuss colloidal gels $^{7,13), 14}$, nor gels made from inorganic salts ${ }^{15}$, and no attention is given to applications. Excellent summaries of current ${ }^{16)}$ and potential ${ }^{17)}$ uses of sol-gel technology are available. It is ironic that the burst of activity in this field dates from the demonstration that monolithic gels can be prepared, whereas the important applications have been, and are likely to remain, in the fabrication of films, fibers, and powders. Good general reviews have been published ${ }^{18), 19)}$, and an extensive list of systems that have been prepared by the sol-gel method is given by Rabinovich ${ }^{20}$. For a broad view of current activity in the field, the interested reader should consult the proceedings of the International Workshops on $\mathrm{Gels}^{21-23)}$, the symposia entitled "Better Ceramics Through 
Chemistry" ${ }^{24), 25)}$, and the conferences on “Ultrastructure Processing”"26),27).

Precursor compounds for the preparation of inorganic oxides are discussed in section 2. The chemistry of hydrolysis and condensation, and the structure of the resulting polymers are the subjects of section 3. Section 4 deals with gelation and aging, and section 5 with drying. The effects of heat treatment prior to sintering are discussed in section 6 , and sintering and crystallization are covered in section 7 . Section 8 provides a comparison of the properties of gelderived and conventionally melted glasses.

\section{Precursor compounds}

The most commonly used precursors in the sol-gel process are metal alkoxides. The chemistry of these compounds is discussed at length by Bradley et al. ${ }^{28)}$ and Andrianov ${ }^{29)}$. The alkoxides are easily hydrolyzed, and the network-forming elements, such as $\mathrm{Si}, \mathrm{B}, \mathrm{Ti}$, and $\mathrm{Al}$, can be polymerized to form a gel, rather than a precipitate. Elements of the first and second column of the periodic table are often added as salts. Nitrates are highly soluble and relatively inexpensive, but they tend to crystallize during drying of the gel $^{30)}$; in addition, they decompose at high temperatures and present an explosion hazard. Levene and Thomas ${ }^{31}$ suggested the use of acetates of those elements. Mackenzie and coworkers $^{32), 33)}$ have shown that silicon can also be introduced as an acetate to produce clear gels.

The reaction is generally represented as partial hydrolysis

$$
\begin{aligned}
& \mathrm{M}(\mathrm{OR})_{n}+m \mathrm{H}_{2} \mathrm{O} \\
& \quad \rightarrow \mathrm{M}(\mathrm{OR})_{n-m}(\mathrm{OH})_{m}+m \mathrm{ROH}
\end{aligned}
$$

followed by condensation

$$
\begin{aligned}
& 2 \mathrm{M}(\mathrm{OR})_{n-m}(\mathrm{OH})_{m} \\
& \quad \rightarrow(\mathrm{RO})_{n-m}(\mathrm{OH})_{m-1} \mathrm{M}-\mathrm{O}-\mathrm{M}(\mathrm{OR})_{n-m}(\mathrm{OH})_{m-1} \\
& \quad+\mathrm{H}_{2} \mathrm{O}
\end{aligned}
$$

where $\mathrm{M}$ is a metallic element and $\mathrm{R}$ is an alkyl $\left(\mathrm{C}_{n} \mathrm{H}_{2 n+1}\right)$ group. These reactions occur concurrently, as explained in the next section. When more than one metal (or metalloid) is involved, it is generally desired to produce $\mathrm{M}-\mathrm{O}-\mathrm{M}^{\prime}$ bonds, and to minimize self-condensation ( $\mathrm{M}-\mathrm{O}-\mathrm{M}$ and $\left.\mathrm{M}^{\prime}-\mathrm{O}-\mathrm{M}^{\prime}\right)$. The choice of precursors is a vital consideration in the preparation of multicomponent gels, because the rates of reaction of the alkoxides vary considerably. For example, if ethoxides of silicon and boron are mixed and water is added, boric acid will precipitate before the silcon ethoxide reacts. An ingenious solution to this problem was proposed by Levene and Thomas $^{31}$. First the slowly-reacting species $\mathrm{M}-\mathrm{OR}$ (usually silicon alkoxide) is mixed with less than the stoichiometric amount of water for hydrolysis to produce one hydroxyl per metal atom ( $m=1$ in reaction 1 , above). Then the more reactive compound $\mathrm{M}^{\prime}-\mathrm{OR}$ is added and it reacts with the hydroxyl to produce an $\mathrm{M}-\mathrm{O}-\mathrm{M}^{\prime}$ bond. Alternatively, homogeneity can be achieved by matching the reactivities of the alkoxides. Since larger alkoxy groups hydrolyze more slowly, the more reactive metal can be introduced using a larger $\mathrm{R}$ group. For example, it would be more favorable to mix $\mathrm{Si}(\mathrm{OR})_{4}$ and $\mathrm{B}\left(\mathrm{OR}^{\prime}\right)_{3}$ using $\mathrm{R}=$ $\mathrm{CH}_{3}$ and $\mathrm{R}^{\prime}=\mathrm{C}_{3} \mathrm{H}_{7}$ than conversely. Yamane et al. ${ }^{34)}$ claim that this method is more effective than the sequential hydrolysis technique ${ }^{31}$. A potential problem with this method is that substantial ligand exchange may occur; that is, the alkoxides may trade $R$ and $R^{\prime}$ groups. This is readily observed when tetramethoxy silane (TMOS), Si $\left(\mathrm{OCH}_{3}\right)_{4}$, is mixed in ethanol ${ }^{35)}$, or tetraethoxy silane (TEOS), $\mathrm{Si}\left(\mathrm{OC}_{2} \mathrm{H}_{5}\right)_{4}, \quad$ is mixed in propanol $^{36}$.

Another method of achieving homogeneity in multicomponent gels is to combine the metal atoms in the precursor. Double alkoxides of $\mathrm{Si}$ and $\mathrm{Al}$ and of $\mathrm{Si}$ and $\mathrm{Ti}$ were prepared by Andrianov and Zhdanov ${ }^{37}$ and hydrolyzed to produce oxides. This technique has been used to make stoichiometric strontium titanate ${ }^{38), 39)}$ from an alkoxide with a $1: 1$ ratio of $\mathrm{Sr}$ to $\mathrm{Ti}$. Similarly, Zelinsky et al. ${ }^{40)}$ used $\mathrm{Mg}\left[\mathrm{Al}(\mathrm{OEt})_{4}\right]_{2}$ and $\mathrm{Ca}\left[\mathrm{Al}(\mathrm{OEt})_{4}\right]_{2}$ (where Et represents the ethyl group, $\mathrm{C}_{2} \mathrm{H}_{5}$ ) to prepare gels of cordierite and anorthite; again, the metal ratios in the precursors are just what are needed in the products.

Morgan et al. ${ }^{41)}$ have demonstrated that heating of metal alkoxides will cause self-condensation into higher molecular weight oils that are soluble in organic solvents. The oils can be used to make films or could perhaps be used as binders in conventional ceramics processing. Other condensation reactions that occur without water are discussed by Schmidt and Scholze ${ }^{42)}$.

In some cases it has been found advantageous to mix colloidal silica ( such as Aerosil ${ }^{\circledR}$, made by flame oxidation of $\mathrm{SiCl}_{4}$ ) into an alkoxide solution during hydrolysis. This has been done to produce relatively thick films ${ }^{43)}$, antireflective coatings $^{44)}$, and to make large silica bodies at low 
$\cos t^{45)}$

A special class of materials with properties intermediate between organic polymers and inorganic oxides can be produced by copolymerizing alkoxides and organic monomers, such as ethoxides and glycols. This field was originally explored by Andrianov ${ }^{29), 37)}$, and has been fruitfully pursued in recent years by Schmidt and colleagues $^{46)}$. This is likely to be one of the most important branches of sol-gel technology, because it offers the possibility of producing truly novel materials. These hybrid materials have been used to make contact lenses ${ }^{47}$, membranes ${ }^{48)}$, adhesives ${ }^{49)}$, ionic conductors ${ }^{50)}$, and materials with modified elastic properties ${ }^{51), 52)}$.

\section{Hydrolysis and condensation}

\section{1 Reaction mechanism}

The hydrolysis and condensation of silica are discussed at length in the superb treatise by Iler ${ }^{53)}$, but the emphasis is on aqueous systems, whereas the sol-gel process usually employs alcoholic solutions. Excellent reviews directed toward the chemistry of such systems have been presented by Schmidt et al. ${ }^{42), 54)}$ and Keefer ${ }^{55)}$. This discussion will focus on the alkoxides of silicon, since there are relatively few data concerning the hydrolysis and condensation of the alkoxides of other elements.

Aelion et al. ${ }^{56)}$ studied the hydrolysis of TEOS in the presence of acid and base. They found that both hydrolysis and condensation were rapid at low $\mathrm{pH}$, but at higher $\mathrm{pH}$ the condensation was controlled by the rate of hydrolysis. Under acidic conditions, the hydrolysis proceeds by an elec-

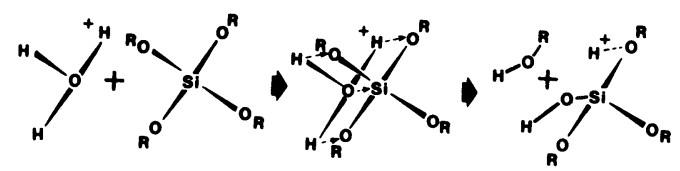

Fig. 1. Acid-catalyzed hydrolysis of silicon alkoxide by electrophilic reaction mechanism (from Keefer ${ }^{55)}$ ). Copyright 1984 by Elsevier Science Publishing Co., Inc. Reprinted by permission of the publisher.

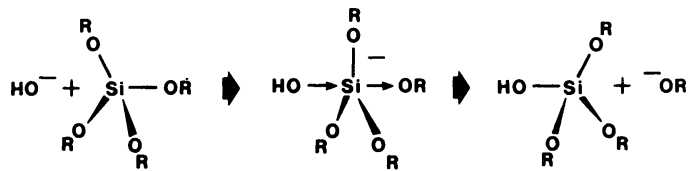

Fig. 2. Base-catalyzed hydrolysis of silicon alkoxide by nucleophilic reaction mechanism, assuming inversion of molecule; $\mathrm{R}=\mathrm{H}, \mathrm{Et}$, or $\mathrm{Si}(\mathrm{OR})_{3}$ (from $\mathrm{Ke}$ efer ${ }^{55)}$ ). Copyright 1984 by Elsevier Science Publishing Co., Inc. Reprinted by permission of the publisher. trophilic mechanism, as illustrated in Fig. 1. Base-catalyzed hydrolysis involves nucleophilic substitution; the transition state may involve a five-coordinated silicon, but that has not been conclusively demonstrated ${ }^{42), 56}$. Keefer $^{55)}$ favors that interpretation, illustrated in Fig. 2. It has been demonstrated by isotopic substitution ${ }^{57}$ that the $\mathrm{Si}-\mathrm{O}$ bond is broken and the OR is replaced by a hydroxyl group from the attacking water molecule :

$$
\equiv \mathrm{Si}-{ }^{18} \mathrm{OR}+\mathrm{H}_{2} \mathrm{O} \rightarrow \equiv \mathrm{SiOH}+\mathrm{R}^{18} \mathrm{OH}
$$

Aelion et al. ${ }^{56)}$ found that the reaction was second order in $\mathrm{H}_{2} \mathrm{O}$ and TEOS when acid-catalyzed, and first order in TEOS when base-catalyzed. However, it is now evident that the reaction order is very difficult to establish because succeeding alkoxy groups may hydrolyze at different rates, and because hydrolysis and condensation take place concurrently. In addition, the $\mathrm{pH}$ may drift under basic conditions $\mathrm{s}^{58}$, because the catalyst is neutralized by the acidic silanol ( $\mathrm{SiOH})$ groups. The effects of such factors on the apparent reaction rate have been discussed in detail ${ }^{551,59), 60)}$.

\section{2 Polymer structure}

Keefer ${ }^{55}$ has provided a persuasive interpretation of the effects of reaction mechanism on polymer structure; the following discussion closely follows his view. He favors the basecatalyzed reaction mechanism illustrated in Fig. 2, in which the hydroxyl approaches from the "bottom" of the tetrahedron; the alkoxy group leaves from the opposite side, and the tetrahedron inverts. This is suggested to be the most likely transition state, because the $\mathrm{OR}$ and $\mathrm{OH}$ are both negatively charged, and this provides the maximum separation of charge. The alkoxy groups around the silicon deter attack by $\mathrm{OH}$ both because of their negative charge and their bulk; therefore, when an OR has been replaced by an $\mathrm{OH}$, hydrolysis of the remaining OR groups is easier. Thus, TEOS is hydrolyzed more slowly than any other monomer, and once hydrolysis of a molecule begins, it tends to go to completion. Above $\mathrm{pH}=2$ (the isoelectric point of silica), the

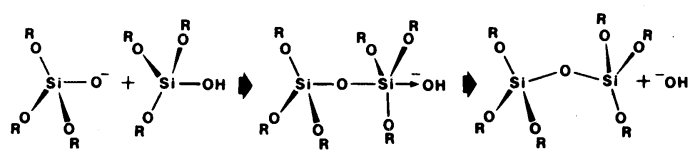

Fig. 3. Nucleophilic condensation reaction mechanism ; $\mathrm{R}=\mathrm{H}, \mathrm{Et}$, or $\mathrm{Si}(\mathrm{OR})_{3}$ (from Keefer ${ }^{55)}$ ). Copyright 1984 by Elsevier Science Publishing Co., Inc. Reprinted by permission of the publisher. 
condensation reaction proceeds ${ }^{53)}$, as illustrated in Fig. 3, by reaction between a deprotonated silanol and a protonated silanol. This means that fully hydrolyzed monomers can make more densely crosslinked polymers, so such polymers are to be expected under basic conditions. Under acidic conditions, as shown in Fig. 1, the attacking group is positively charged, so it is more attracted to a monomer having more (negatively charged) OR groups. Therefore, the $\mathrm{Si}(\mathrm{OR})_{4}$ monomer is most rapidly hydrolyzed, and the reaction of the remaining OR groups is progressively slower. This means that condensation is likely to occur before the monomer is fully hydrolyzed; the resulting polymer will tend to be lightly crosslinked, because fewer condensation sites are present. Thus, base catalysis tends to produce densely crosslinked polymers, and acid catalysis tends toward more linear, lightly crosslinked polymers. These tendencies are sensitive to factors other than $\mathrm{pH}$. A high water concentration favors hydrolysis and inhibits condensation, since water is the product of that reaction. Therefore, even under acidic conditions, excess water favors a higher crosslink density. Also, since the condensation rate has a minimum at $\mathrm{pH} \approx 2$, in that $\mathrm{pH}$ range hydrolysis may be complete before significant condensation occurs.

Keefer ${ }^{55}$ points out that when the water concentration is low, even at high $\mathrm{pH}$, condensation may begin before hydrolysis is complete. This suggestion is supported by small angle X-ray scattering (SAXS) data ${ }^{55), 61}$, which show that less densely crosslinked polymers are formed under basic conditions when the concentration of water is decreased. At higher water content, the particles have dense cores and rough surfaces. Computer models ${ }^{61), 62)}$ suggest that this sort of structure results from partially hydrolyzed monomers adding to the growing cluster, followed by slow hydrolysis of the cluster to provide additional growth sites. If hydrolysis requires inversion of the molecule, further hydrolysis will be quite difficult once condensation has occurred. Brinker et al. ${ }^{36)}$ have shown that hydrolysis of partially condensed $\mathrm{Si}(\mathrm{OR})_{4-n}(\mathrm{OH})_{n}$ species goes to completion under basic conditions, so it is not clear whether inversion is required. However, it seems clear that clusters grow by addition of monomers under basic conditions (since dense particles can be produced in this case), whereas growth occurs by cluster/cluster aggregation under acidic condi-

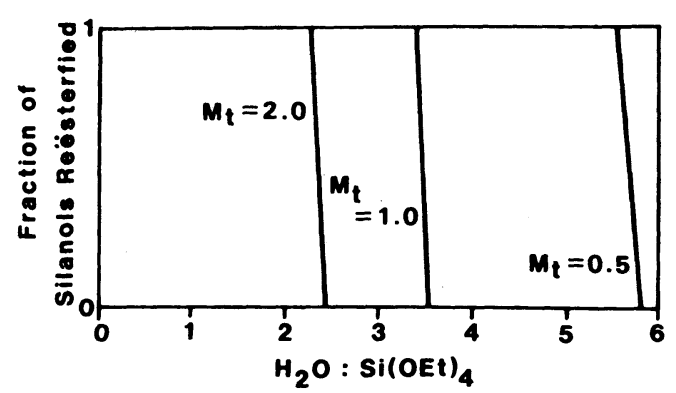

Fig. 4. Calculated fraction of silanols in gel that reesterify upon evaporation of ethanol solvent, as function of $\mathrm{H}_{2} \mathrm{O}: \mathrm{Si}(\mathrm{OEt})_{4}$ at different molar concentrations of $\mathrm{Si}(\mathrm{OEt})_{4}, M_{\mathrm{t}}$. Calculated at $78^{\circ} \mathrm{C}$, assuming complete solution hydrolysis, degree of polymerization of 3 , and neglecting $\Delta V$ of mixing (from Keefer ${ }^{55)}$ ). Copyright 1984 by Elsevier Science Publishing Co., Inc. Reprinted by permission of the publisher.

tions (which always produce highly branched structures).

Under acidic conditions, hydrolysis is rapid even after condensation. Interestingly, the reverse reaction (called reesterification) is also relatively easy, and is promoted by the large quantity of alcohol usually used as a solvent in the sol-gel process. Therefore, hydrolysis may go to completion, but the resulting gel may contain a large quantity of SiOR groups that are produced during aging and drying of the gel. The extent of reesterification is shown in Fig. 4. Since retained organics cause difficulty during heat treatment of the gel, it is clearly advantageous to use excess water during hydrolysis. It would also be beneficial to use a solvent, such as tetrahydrofuran, that is not a reactant.

Brinker and his colleagues have performed an excellent study ${ }^{36}$ of the hydrolysis and condensation of a silica gel made by a two-step process. The first step consists of hydrolysis under acidic conditions $(\mathrm{pH}=0.3)$, with the reactants added in the molar ratio TEOS/alcohol $/ \mathrm{H}_{2} \mathrm{O} / \mathrm{HCl}=$ $1 / 3 / 1 / 0.0007$. This causes rapid hydrolysis, but the reaction cannot go to completion, because of the sub-stoichiometric quantity of water. This is followed by addition of more water and catalyst (either $\mathrm{HCl}$ or $\mathrm{NH}_{4} \mathrm{OH}$ ). The progress of the reaction was followed by gas chromatography (GC) and ${ }^{1} \mathrm{H}$ nuclear magnetic resonance (NMR). In the first step, the $\mathrm{GC}$ results indicate that the water is consumed and fully esterified polymers of the form $\mathrm{SiO}(\mathrm{OR})_{2}$ are produced. The $\mathrm{NMR}$ results, which are more reliable, show the formation of $\mathrm{Si}(\mathrm{OR})_{4-n}(\mathrm{OH})_{n}$ with $n=1,2$ and possibly 
3 ; the monomers condense primarily to dimers within 90 minutes, and to dimers plus chains or cyclic polymers after 24 hours. These results are consistent with the discussion above, where it was suggested that acid catalysis at low water concentration should promote condensation before complete hydrolysis, with the formation of lightly crosslinked polymers. In the second stage, some samples (designated A 2) were prepared with a final $\mathrm{pH}$ of 0.95 and $\mathrm{H}_{2} \mathrm{O} / \mathrm{TEOS}=$ 5.1 , while others (B 2) were adjusted to $\mathrm{pH}=7.8$ and $\mathrm{H}_{2} \mathrm{O} / \mathrm{TEOS}=3.7$. The hydrolysis of $\mathrm{A} 2$ goes to completion quickly, but unhydrolyzed TEOS remains in B 2 after condensation is complete; this may indicate phase separation in the base-catalyzed system. The NMR results are discussed in detail by Assink and $\mathrm{Kay}^{63)}$.

The structures of the A 2 and B 2 polymers were studied using SAXS by Schaefer and Keefer ${ }^{36)(64)}$. They showed that neither sample contained colloidal particles of dense silica, but that each consisted of fractal clusters. A fractal body has a structure that becomes increasingly wispy as its radius increases, so that its mass increases in proportion to $r^{d}$, where $r$ is the radius of the cluster and $d$, called the fractal dimension, is smaller than 3. The A 2 polymers were found to be lightly crosslinked compared to the clusters in the B 2 solution. This is demonstrated in Fig. 5 , which shows the effect of dilution on the measured correlation length, $\xi$. In a concentrated solution, $\xi$ represents the mean spacing between entanglements of polymers; in a dilute solution, $\xi$ approaches the radius of gyration, $R_{\mathrm{g}}$, as the polymers disentangle. In the acid-catalyzed system, dilution causes a large difference to appear between $\xi$ and $R_{\mathrm{g}}$. This does not occur in the base-catalyzed solution, because the polymers are relatively compact clusters that do not interpenetrate, even when concentrated.

Results similar to these have been reported by others; much of this work has been reviewed by Brinker and Scherer ${ }^{65)}$. Strawbridge et al. ${ }^{66)}$ used SAXS to examine polymers made by acidcatalyzed hydrolysis of TEOS and found that no colloidal particles were formed. Kelts et al. ${ }^{35}$ used both ${ }^{1} \mathrm{H}$ and ${ }^{29} \mathrm{Si}$ NMR to study the hydrolysis and condensation of TEOS and TMOS. They measured the fraction $Q_{n}$ of $\mathrm{Si}$ atoms bonded through oxygen to $n$ other $\mathrm{Si}$ atoms [thus $Q_{0}=$ monomer and $Q_{4}=$ fully condensed species, $\mathrm{Si}$ $\left.(\mathrm{OSi})_{4}\right]$. When the solution was about to gel, for
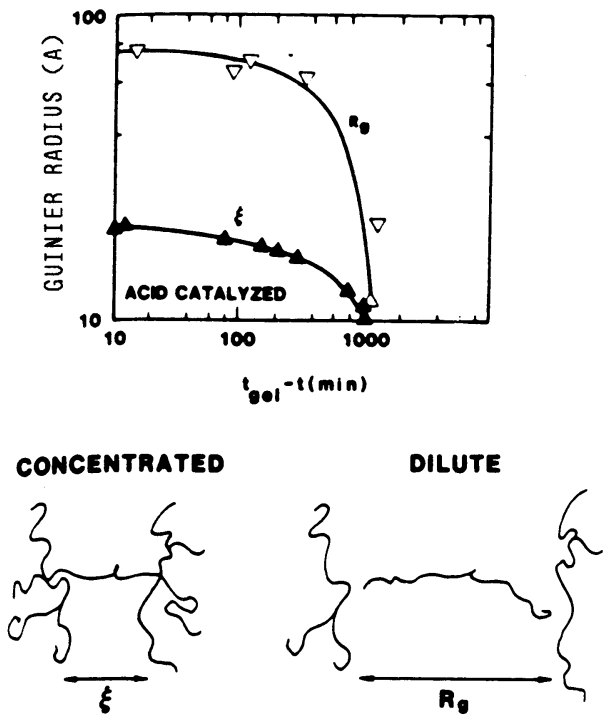

( a )

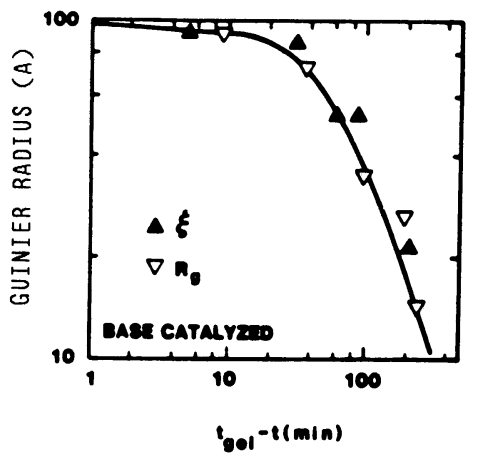

CONCENTRATED

DILUTE
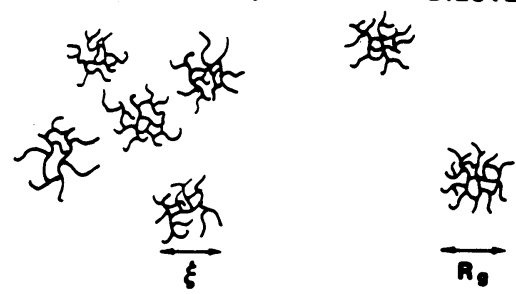

( b )

Fig.5. (a) Guinier radius as function of time to gelation for A 2. The correlation range, $\xi$, is measured on undiluted (concentrated) samples while the radius of gyration, $R_{\mathbf{g}}$, is measured on diluted samples. (b) Guinier radius as a function of time to gelation for B 2 (from Brinker et al. ${ }^{36)}$ ).

those silicon atoms with $n>0,60 \%$ were $Q_{4}$ in a solution with $\mathrm{pH}=7.8$; in contrast, $26 \%$ were $Q_{4}$ at $\mathrm{pH}<1$. That is, the polymers were much more highly condensed under basic conditions. Ruben and Shafer ${ }^{67}$ used high resolution transmission electron microscopy (TEM) to examine acidcatalyzed TMOS gels and colloidal gels made under basic conditions according to Shoup's ${ }^{\text {7) }}$ 
procedure. The photos suggest that linear silica chains are formed under acidic conditions, and highly branched structures form under basic conditions. Sakka et al. ${ }^{68}$ ) used measurements of intrinsic viscosity to show that acid-catalyzed hydrolysis produced linear polymers when the $\mathrm{H}_{2} \mathrm{O} /$ TEOS ratio was $1 / 1$, and highly condensed species when the ratio was 20/1. In a much more complex system $\left(\mathrm{Na}_{2} \mathrm{O}-\mathrm{ZrO}_{2}-\mathrm{SiO}_{2}-\mathrm{P}_{2} \mathrm{O}_{5}\right)$, Dauger et al. ${ }^{69)}$ used ${ }^{29} \mathrm{Si}$ NMR and SAXS to demonstrate that branched polymers, rather than colloidal particles, were formed.

Under conditions of high water concentration and high $\mathrm{pH}$ it certainly is possible to form particles, rather than extended polymers, as in the preparation of silica spheres by the method of Stober et al. ${ }^{70)}$ Sakka and Kamiya ${ }^{71)}$ used rheological measurements to show that particle-like species were formed when TEOS was hydrolyzed under basic conditions or when acid catalysis was combined with a 20/1 ratio of $\mathrm{H}_{2} \mathrm{O} / \mathrm{TEOS}$. Orgaz and Rawson ${ }^{72)}$ used a similar technique to reach the same conclusion about solutions of TEOS catalyzed with a very high acid concentration $(12.4 \%)$.

Several authors have attempted to infer the structure of silicate polymers from their stoichiometry. Bechtold et al. ${ }^{73)}$ concluded that acid-catalyzed hydrolysis of TEOS produces polymers in the form of triple chains. Iler ${ }^{53}$ disputed that interpretation, concluding that aggregation of small dense particles is more likely. Recently Yoldas $^{74)}$ proposed a model in which spherical particles are formed with dense cores and hydroxylated surfaces. These models are not consistent with the evidence presented above, which indicates the formation of fractal polymeric structures. Keefer ${ }^{62)}$ used a simple computer model to generate clusters, and found that fractal structures appeared if the monomers contained a variety of unreactive sites. The real situation may involve many types of monomers and oligomers with different reactivities. Zarzycki ${ }^{75)}$ interprets the SAXS data of Schaefer and Keefer ${ }^{36}$ to indicate that gelation occurs by aggregation of clusters. This has also been suggested by Yoldas $^{76)}$ (on the basis of other evidence), and is consistent with the bimodal pore size distributions often seen ${ }^{76,77)}$ in gels. There is clearly a need for more sophisticated computer modelling of this problem, realistically taking account of the chemistry of the system, and the possibility of cluster/cluster aggregation.

\subsection{Influence of reaction conditions}

It is clear from the preceding discussion that considerable insight has been gained into the mechanism of reaction and the development of gel structure. However, our understanding is limited to the broad principles, while the details are so complicated that the need for empirical studies cannot be overstated. In this section, some of the factors that influence the development of gel structure are examined.

As shown in Fig. 6, there is a large area of immiscibility in the $\mathrm{Si}(\mathrm{OR})_{4} / \mathrm{H}_{2} \mathrm{O} / \mathrm{ROH}$ systems. That would obviously hinder hydrolysis, so a substantial amount of solvent (usually alcohol) must be added. Since alcohol is the product of the hydrolysis reaction, large concentrations of alcohol can inhibit the net rate of hydrolysis, by accelerating the back-reaction (esterification). There is evidence ${ }^{36)}$ that phase separation can develop in initially homogeneous solutions when

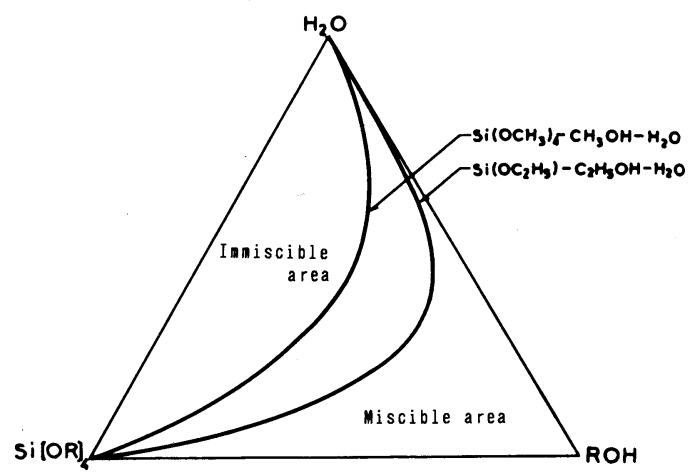

Fig.6. Miscibility diagram of the ternary system $\mathrm{Si}(\mathrm{OR})_{4}-\mathrm{ROH}-\mathrm{H}_{2} \mathrm{O}$ (from Prassas and $\mathrm{Hench}^{182)}$ ). Copyright $\left.^{(}\right) 1984$ by John Wiley \& Sons, Inc. Reprinted by permission of the publisher.

RESULTS AND DISCUSSION

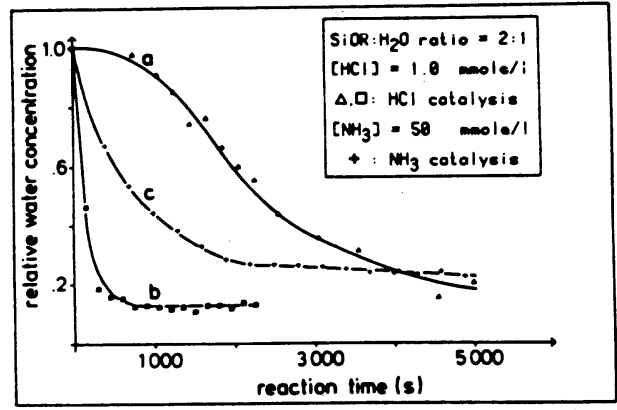

Fig. 7. Hydrolysis of TEOS with $\mathrm{HCl}$ catalysis (curve a) and of TMOS with $\mathrm{HCl}$ (curve b) and $\mathrm{NH}_{3}$ catalysis (curve c) (from Schmidt et al. ${ }^{59)}$ ). Copyright ${ }^{\complement} 1986$ by John Wiley \& Sons, Inc. Reprinted by permission of the publisher. 
Table 1. Material rate constants $k$ for acid-catalyzed hydrolysis of tetraalkoxysilanes $\mathrm{Si}(\mathrm{OR})_{4}$.

\begin{tabular}{ll}
\hline $\mathrm{Si}(\mathrm{OR})_{4}$ & $k\left(1 \mathrm{~mol}^{-1} \mathrm{~s}^{-1}\left[\mathrm{H}^{+}\right]^{-1}\right)$ \\
\hline $\mathrm{Si}\left(\mathrm{OCH}_{3}\right)_{4}$ & 0.19 \\
$\mathrm{Si}\left(\mathrm{OC}_{2} \mathrm{H}_{5}\right)_{4}$ & 0.051 \\
$\mathrm{Si}\left(\mathrm{OC}_{4} \mathrm{H}_{9}\right)_{4}$ & 0.019 \\
$\mathrm{Si}\left(\mathrm{OC}_{6} \mathrm{H}_{13}\right)_{4}$ & 0.0083 \\
\end{tabular}

From Chen et al (33)

hydrolysis is carried out under basic conditions. It has been suggested ${ }^{64)}$ that this may be responsible for the cloudiness of gels produced with a basic catalyst. Following a suggestion by Dislich $^{3)}$, Puyane et al. ${ }^{78)}$ found that the addition of a chelating agent (acetyl acetonate) gave clearer gels.

Aelion et al. ${ }^{56)}$ showed that the rate of hydrolysis decreases as the size of the alkoxy ligand increases; Table 1 (from Ref. 33)) summarizes the available data. The magnitude of the effect is shown in Fig. 7. Yoldas ${ }^{79}$ reports that smaller ligands lead to polymers with a higher oxide content (i. e. more highly condensed). Schmidt et al. ${ }^{54)}$ demonstrated that a molecule such as $\mathrm{R}_{n}{ }_{n} \mathrm{Si}(\mathrm{OR})_{4-n}$, where $\mathrm{R}^{\prime}$ is an alkyl, hydrolyzes faster than $\mathrm{Si}(\mathrm{OR})_{4}$ when acid-catalyzed, but more slowly when base-catalyzed. Sakka et al. ${ }^{80)}$ hydrolyzed $\mathrm{Si}\left(\mathrm{OC}_{2} \mathrm{H}_{5}\right)_{3} \mathrm{CH}_{3}$ and $\mathrm{Si}\left(\mathrm{OC}_{2} \mathrm{H}_{5}\right)_{2}$ $\left(\mathrm{CH}_{3}\right)_{2}$ (designated $\mathrm{M}_{1}$ and $\mathrm{M}_{2}$, respectively), and found that $M_{1}$ produced linear chains while $\mathrm{M}_{2}$ produced rings that would not gel. Mackenzie and coworkers ${ }^{33,81)}$ studied the behavior of several alkoxides and the acetate of silicon and found important differences in the time required to gel, $t_{\mathrm{g}}$, and in the density and surface area of the dried gels. An increase in $t_{\mathrm{g}}$ can be interpreted as a decrease in condensation rate, on the assumption that the mechanism of gelation does not change.

The choice of solvent is important, because ligand exchange can occur rapidly ${ }^{35,36)}$. For example, if TMOS is dissolved in ethanol, some of the methoxy groups will be replaced by ethoxy groups which hydrolyze more slowly. Mackenzie ${ }^{81}$ showed that the vapor pressure of the solvent has an important effect on $t_{\mathbf{g}}$ and on the surface area of the resulting gel. When the vapor pressure is low, the solution gels with a larger amount of included liquid, so the dried gel has a more open structure. The amount of solvent (i. e. the dilution of the solution) affects the rate of reaction. Yoldas ${ }^{76)}$ used ${ }^{29} \mathrm{Si}$ NMR to show that the condensation rate decreases when the solution is diluted with alcohol, and attributed the effect to the increased diffusion distance in the dilute solution. The effect might also be attributed to a change in equilibrium caused by excess alcohol inhibiting the hydrolysis. Bechtold et al. ${ }^{73}$ showed that $t_{\mathbf{g}}$ increases when the solution is diluted with either alcohol or water, when the dilution is performed after hydrolysis.

The ratio $r=\mathrm{H}_{2} \mathrm{O} /$ alkoxide is one of the most important factors controlling the structure of the gel. Schmidt et al. ${ }^{59)}$ found that the rate of hydrolysis decreases as $r$ increases in acidcatalyzed TMOS solutions, but the rate increases with $r$ with a basic catalyst. They argued that the additional water helps to dissociate the ammonia, making it a more effective catalyst; in the other case, the extra water serves to reduce the activity of the (fully dissociated) proton of the acid. Excess water accelerates gelation ${ }^{82,83)}$, as shown in Fig. 8. Increasing $r$ reduces the amount of retained organics in the dried gel ${ }^{74), 83), 84)}$ since, as mentioned above, the water helps to prevent reesterification. The surface area and density of the dried gel also are affected by $r^{83,85)}$.

The importance of the catalyst has been recognized since Nogami and Moriya ${ }^{86)}$ showed the influence of $\mathrm{pH}$ on the structure of silica gels. In systems catalyzed by mineral acids, such as $\mathrm{HCl}$ or $\mathrm{HNO}_{3}$, the gels tend to be dense $\left(\sim 1.5 \mathrm{~g} / \mathrm{cm}^{3}\right)$ with very small pores $(<4 \mathrm{~nm})$, and have no discernible microstructure in the TEM; higher $\mathrm{pH}$ leads to lower density, larger pores, and a granular texture observable by $\mathrm{TEM}^{86,87)}$. The effect of $\mathrm{pH}$ has been discussed at length, but Mackenzie ${ }^{81)}$ showed that catalysts such as $\mathrm{HF}$,

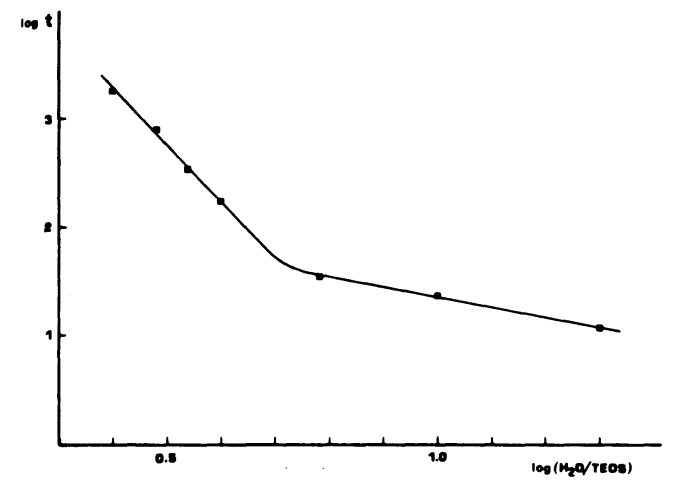

Fig. 8. Logarithm of gelling time versus log $\left(\mathrm{H}_{2} \mathrm{O} / \mathrm{TEOS}\right)$. The solutions were kept in closed flasks at $60^{\circ} \mathrm{C}$ until no flow was observed (from Gottardi et al. ${ }^{82)}$ ). 
$\mathrm{HCl}, \mathrm{HBr}$, and $\mathrm{HI}$ have a profound effect on gel structure that does not correlate with $\mathrm{pH}$. Most interesting is the effect of $\mathrm{HF}$, which causes the gel to have a structure more closely resembling an $\mathrm{NH}_{3}$-catalyzed system than an $\mathrm{HCl}$-catalyzed system. Colby et al. ${ }^{88)}$ showed that $\mathrm{HF}$ reduces $t_{\mathbf{g}}$ by a factor of $\sim 50$ compared to $\mathrm{HCl}$. $\mathrm{HF}$-catalyzed gels also have less tendency to reboil, as described in section 6 .

M. Prassas showed that gels have less tendency to crack during drying if the alcohol solvent is replaced with a liquid such as formamide or glycerol having a low vapor pressure. The slow evaporation of these liquids (called "drying control chemical additives“, DCCA) was believed to reduce the differential contraction that causes cracking. This work has been vigorously pursued by Hench and coworkers ${ }^{89-92}$, and is discussed further in section 5 . Formamide has been shown ${ }^{931-95)}$ to decrease the rate of hydrolysis of TMOS and increase the rate of condensation. The resulting gels have larger pores, a narrower distribution of pore sizes, and are stronger ${ }^{89)}$. It is not clear how these structural differences are related to the changes in reaction rates. Coarser gels are produced in systems with higher $\mathrm{pH}$, but formamide decreases the $\mathrm{pH}^{93)}$. Mackenzie ${ }^{81)}$ showed that larger pore volumes result when solvents with low vapor pressure are used, but he did not report on the pore size distribution or hardness of the resulting gels.

\section{Gelation and aging}

As the polymers in solution grow by condensation reactions, they link together into larger and larger clusters until one cluster spans the whole solution. This point represents the sol to gel transition, and is easily recognized by the sudden increase in viscosity of the solution. As indicated in Fig. 9, at the time of gelation there may be many small polymers that are not attached to the spanning cluster. Flory ${ }^{96}$ showed that the average molecular weight of the polymers in the sol phase decreases after gelation, as polymers continue to attach to the gel network. That sort of behavior is illustrated in light scattering data obtained during the acid-catalyzed gelation of $\operatorname{TEOS}^{97}$, as shown in Fig. 10. The diffusion coefficient $D_{1}$ decreases as the polymers grow, until they reach a diameter of $\sim 25 \mathrm{~nm}$. At that point a second species, characterized by diffusion coefficient $D_{2}$, appears; this is near the time when gelation is

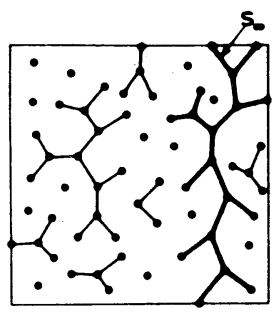

a

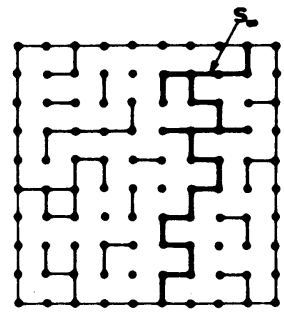

b
Fig. 9. Gelation theories (schematic): (a) Flory's model ; (b) percolation on a square lattice. In each case a spanning $\mathrm{s}_{\infty}$ cluster is indicated embedded in the sol (from Zarzycki $^{75)}$ ). Copyright ${ }^{\complement} 1986$ by John Wiley \& Sons, Inc. Reprinted by permission of the publisher.

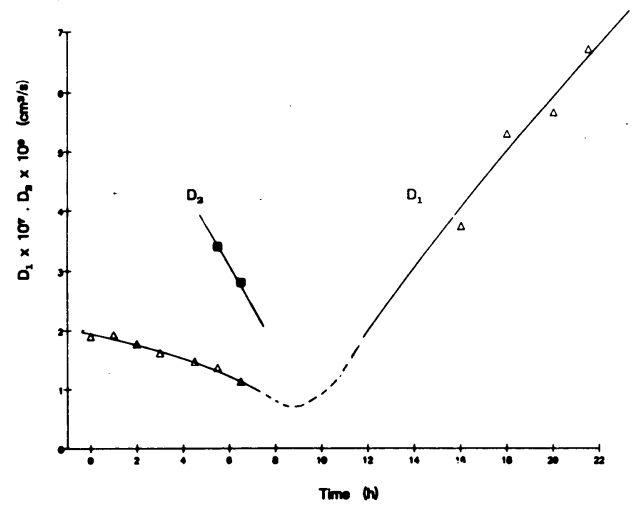

Fig. 10. Diffusion coefficients measured by photon correlation light spectroscopy on an acidic solution of TEOS; $D_{1}$ represents small clusters that grow for $\sim 9$ hours (near $t_{\mathbf{g}}$ ) then shrink; $D_{2}$ either represents large clusters $(>1 \mu \mathrm{m})$ or thermal density fluctuations in the gel network (from Flippen and Scherer ${ }^{97)}$ ).

detected visually (by loss of fluidity). The second diffusion coefficient either represents very large particles $(>1 \mu \mathrm{m})$ or thermal fluctuations of the gel network. In the latter case, Tanaka et al. ${ }^{98)}$ have shown that $D_{2}=E D / \eta_{\mathrm{L}}$, where $E$ is the elastic modulus of the network, $D$ is the permeability of the gel to fluid flow (discussed further in the next section), and $\eta_{\mathrm{L}}$ is the viscosity of the solvent. After the network (i.e. $D_{2}$ ) appears, $D_{1}$ increases; this indicates that the average size of the polymers in the sol decreases, as predicted by Flory's theory. The classical theory ${ }^{96)}$ assumes that each branch of the network splits further and further, without forming closed loops. It has been shown ${ }^{99)}$ that this leads to unrealistic crowding at the periphery of the growing cluster, such that the mass of the cluster grows as (radius) $)^{4}$. Therefore the model is applicable only to the early stages of cluster growth, or when gelation occurs by linking of long linear polymers. The standard example of the latter case 
is vulcanization of rubber, but it might also describe gelation of silica under acidic conditions. Percolation theory ${ }^{100}$ describes gelation on a fixed lattice and predicts the growth of realistic fractal objects, but does not offer closedform solutions, as Flory's model does, for such properties as the molecular weight distribution of the sol. If $p$ is the fraction of all possible bonds that have already formed, then the value of $p$ at the sol/gel transition depends on the geometry of the percolation lattice. However, geometryindependent scaling laws have been established ${ }^{99,100)}$ that indicate the dependence of properties such as viscosity or elastic modulus on $p$. Zarzycki ${ }^{75}$ has shown that the available data on gels are in reasonable agreement with the scaling laws.

The sudden increase in viscosity of a sol is the most common method for establishing the time $\left(t_{\mathrm{g}}\right)$ of the sol/gel transition (e.g. $\left.{ }^{88)}\right)$. As the clusters grow, the measuring instrument (such as a rotating spindle) breaks the clusters, so the viscosity depends on the applied shear rate; this is called shear thinning behavior. Sometimes the transition is defined by the point at which the spindle tears away from the ge ${ }^{58)}$. A more appropriate definition for $t_{\mathrm{g}}$, suggested by Sacks and Sheu ${ }^{101)}$, is the appearance of a yield stress in the sol, which indicates that the spanning cluster has formed. It may also be possible to use light scattering data of the sort illustrated in Fig. 10 to identify $t_{\mathrm{g}}$ by the appearance of $D_{2}$.

Gelation is often induced by exposing the sol to the atmosphere, so that the solvent can evaporate and ambient moisture can diffuse into the solution. This causes the sample to gel gradually from the surface inward, and can cause cracking ${ }^{10)}$. A more uniform and reproducible method, suggested by Klein and Garvey ${ }^{1022}$, is to reflux the sol to promote condensation reactions, then to strip out the excess solvent to obtain a sol of a particular density that will gel in a reproducible period of time. Studies using ${ }^{29} \mathrm{Si}^{103)}$ show that 30 minutes of refluxing produces a degree of reaction that requires 20 hours at room temperature, and 3 hours of refluxing is equivalent to more than a week at ambient. No detectable changes result when the density of the solution is quickly raised to $1.1 \mathrm{~g} / \mathrm{cm}^{3}$ by evaporation under reduced pressure.

The rate of gelation depends on many factors, some of which were mentioned in section 3 .

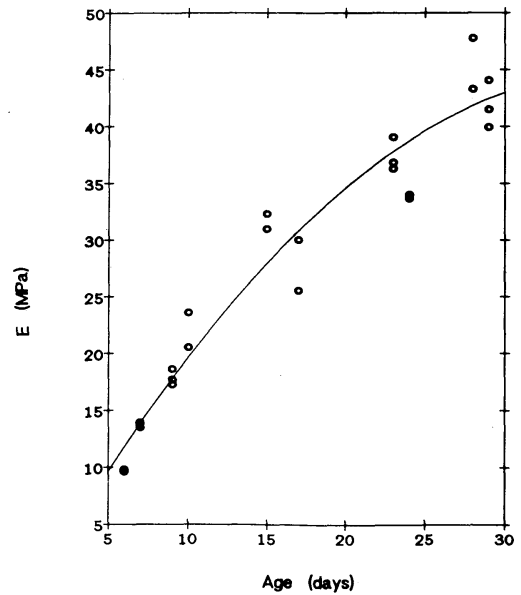

Fig. 11. Elastic modulus of wet silica gel determined by 3-point bending with samples immersed in solvent; samples aged at room temperature in closed containers (from Scherer and Swiatek ${ }^{108)}$ ).

Increasing temperature decreases $t_{\mathbf{g}}$; the apparent activation energy for silicon alkoxides is in the range of $10-20 \mathrm{kcal} / \mathrm{mole}^{20), 104), 105)}$ depending on the catalyst and the alkoxy group. Gelation time also decreases with increases in $\mathrm{H}_{2} \mathrm{O} / \mathrm{Si}(\mathrm{OR})_{4}{ }^{82)},{ }^{104)}$, alkoxide concentration ${ }^{83), 104)}$, and $\mathrm{pH}$ with a minimum in $t_{\mathrm{g}}$ at $\mathrm{pH}=8^{105)}$. Various DCCA also affect $t_{\mathbf{g}^{94)}}$.

The properties and structure of the gel continue to change long after $t_{\mathrm{g}}$, because smaller polymers continue to attach to the spanning cluster. Changes in the degree of condensation can be observed long after gelation by ${ }^{29} \mathrm{Si} \mathrm{NMR}^{35)}$ and Raman spectroscopy ${ }^{106}$. As the connectivity of the network increases, so does the elastic modulus of the gel ${ }^{107), 108)}$, as shown in Fig. 11. These structural changes, known as aging, are particularly pronounced at high $\mathrm{pH}^{53)}$, because the enhanced solubility of silica allows dissolution and reprecipitation, which leads to coarsening of the pore structure. Since a stiffer network is better able to resist the capillary pressure during drying, aging may be responsible for the observation that slower drying ${ }^{109}$ and higher $\mathrm{pH}^{86)}$ produce gels with greater pore volume. The larger pore volumes obtained with the DCCA formamide ${ }^{89 !}$ may result in part from rapid aging caused by acceleration of condensation reactions ${ }^{93}$.

As condensation reactions proceed, the gel structure contracts and exudes solvent in a process called syneresis. This contraction may also be driven by the large interfacial energy of the gel, as discussed in the next section. The rate of 
syneresis increases with temperature. An extreme example of syneresis was illustrated by Partlow and Yoldas ${ }^{10)}$ using a titania gel.

In some cases, aging causes undesirable changes in the gel. For example, Prassas et al. ${ }^{111}$ found that $\mathrm{Na}_{2} \mathrm{O}-\mathrm{SiO}_{2}$ gels react with ambient $\mathrm{CO}_{2}$ to produce sodium carbonate crystals, so that the gel becomes inhomogeneous. Dauger et al. ${ }^{69)}$ discovered precipitation of $\mathrm{ZrO}_{2}$ crystals in a four-component gel.

It is difficult to obtain structural information about the wet gel. SAXS gives an estimate of the average pore or particle size, and light scattering gives the elastic modulus and permeability, but most workers prefer to use familiar techniques such as TEM and nitrogen adsorption, which require drying of the gel. Since the gel contracts substantially during drying, the structure changes. Shrinkage may be suppressed during freeze-drying, but the structure may be damaged if the solvent crystallizes; hypercritical drying prevents shrinkage, but may nevertheless promote chemical and structural changes. A promising technique, called thermoporometry, for nondestructive measurement of gel structure has been developed by Brun et al. ${ }^{112)}$ It is based on the fact that the freezing point of a liquid is depressed if the liquid-crystal interface is curved; therefore, the freezing point of the pore liquid depends on the pore size. By measuring the heat released and absorbed during cooling and heating, it is possible to determine the pore size distribution. Quinson et al. ${ }^{113)}$ used this technique on an acid-catalyzed TEOS gel, and showed a very narrow distribution of pore radii with an average value of $2.5 \mathrm{~nm}$. Unfortunately, it is necessary to insure that the liquid in the pores is pure water, so the gel must be rinsed for several days in flowing water, which could cause structural changes. However, there is no discernible dilatation of the gel during such treatment.

\section{Drying}

The most difficult and time-consuming step in the preparation of glass from a gel is removal of the solvent (drying). To avoid cracking the drying rate must be extremely slow : days, and even months, may be needed to dry a gel $1 \mathrm{~cm}$ thick without cracking; the larger the gel, the longer the time required. This problem has been discussed by Iler ${ }^{53)}$ and by Zarzycki et al. ${ }^{114), 115)}$ As liquid evaporates from the gel, the small pore size causes large capillary stresses to develop, and these can cause cracking. Therefore, larger pore sizes and a stronger gel network tend to reduce the amount of cracking. It has been $\operatorname{argued}^{114), 115)}$ that a distribution of pore sizes is harmful, because smaller pores experience larger stresses; if neighboring pores have different radii, differential stresses appear that produce cracks. This is consistent with the observation that the DCCA that allow faster drying produce narrower pore size distributions ${ }^{92)}$ and stiffer gels $^{91}$. However, it is not clear how slower drying would prevent cracking if the problem were the distribution of pore sizes. In this section, a model is presented that shows that large stresses will appear even if the pore size of the gel is uniform. The stress is proportional to the drying rate and to the thickness of the gel ; larger pores and a stiffer network are shown to reduce the stress.

Cooper ${ }^{16)}$ proposed a model to describe the drying of clays. He suggested that evaporation of water from the surface of the body causes a gradient in water content and a corresponding gradient in contraction, which produces stresses. Transport of liquid was assumed to occur by diffusion, and the mechanical properties of the solid phase did not enter into the model. Zarzycki ${ }^{115)}$ pointed out that the driving force for contraction is not the concentration gradient of water, but rather the gradient in moisture stress, $\psi$. The moisture stress is the change in free energy of a body when the liquid content changes ${ }^{117)}$. There are contributions to $\psi$ from capillarity, osmotic forces, and disjoining pressure (repulsive forces from charges on a pore wall that tend to keep the pore open), among other things. Since inorganic gels show little tendency to dilate when immersed in different solvents or exposed to changes in electrolyte concentration, it seems that the dominant contribution to $\psi$ is the capillary force arising from the large interfacial area of the gel. Another defect of Cooper's model is that the liquid is assumed to diffuse to the surface. In a porous material such as a gel, fluid is not transported by diffusion, but rather by flow down a pressure gradient according to Darcy's law,

$$
J=\left(D / \eta_{\mathrm{L}}\right) \nabla P
$$

where $J$ is the flux [volume/(area $\times$ time $)], D$ is the permeability (in units of area), $\eta_{\mathrm{L}}$ is the viscosity of the liquid, and $\nabla P$ is the gradient of pressure in the liquid. Models based on Darcy's 
law have been presented to describe drying of clays $^{118)}$ and swelling of soils ${ }^{119)}$, but they do not take account of the viscoelastic properties of the solid phase. Tanaka and Fillmore ${ }^{120)}$ developed a model of shrinkage of a gel using Darcy's law (implicitly) and treating the solid phase as perfectly elastic. However, wet inorganic gels exhibit viscous flow ${ }^{121}$, so a new model has been developed ${ }^{122)}$ based on the assumptions that fluid flows according to Eq. ( 4 ), that the contraction is driven by the interfacial energy, and that the solid phase of the gel is viscous. That model is outlined here.

\section{1 Theory for viscous gels}

As liquid evaporates from the surface of the gel, the solid-liquid interface (with energy $\gamma_{\mathrm{SL}}$ ) is replaced by solid-vapor interface (with energy $\left.\gamma_{\mathrm{sv}}\right)$. Since $\gamma_{\mathrm{sv}}>\gamma_{\mathrm{sL}}$, the liquid tends to spread over the exposed area. As the liquid stretches forward, tensile stress develops in the liquid and compressive stress is imposed on the solid phase. In effect, the solid phase is sucked back into the liquid. The maximum magnitude of the tension in the liquid is $P_{\mathrm{R}}$, which is proportional to $\left(\gamma_{\mathrm{sv}}-\gamma_{\mathrm{sL}}\right) S$, where $S$ is the specific surface area of the solid phase. The pressure in the liquid will be only as high as necessary to draw the solid phase into the liquid at the rate that the liquid evaporates; that is, the pressure will rise until the contraction rate of the solid phase equals the rate of volume loss by evaporation. The greater the evaporation rate, the closer the pressure gets to $P_{\mathrm{R}}$. If the permeability of the gel is low (flow through the pores is difficult), then the pressure in the liquid and the contraction of the gel will be confined to the region near the exterior surface. In that case, the exterior will contract faster than the interior of the gel, and tensile stresses will develop in the exterior. If evaporation occurs from one side of a slab of gel, it will tend to warp, becoming concave toward the drying side. As the gel contracts, the stiffness of the solid phase increases until a point is reached at which the solid can no longer retract into the liquid; then the liquid-vapor meniscus penetrates into the gel. The capillary pressure $P_{\mathbf{R}}$ in the liquid causes the saturated region to contract more than the dry exterior region, so the exterior goes into compression. If evaporation occurs from one side, the direction of warping reverses, and the slab becomes convex toward the drying side.

The rate of shrinkage depends on the pressure in the pore liquid. When the pressure in a region is tensile, liquid tends to flow into that region; at the same time, the surrounding solid network is placed in compression and contracts, which also reduces the pressure. This interplay of fluid flow and network deformation is governed by a simple differential equation ${ }^{122)}$ that can be solved for the pressure in the liquid, $P$. The linear strain rate of the gel can be found from

$$
\dot{\epsilon}_{\mathrm{f}}=\dot{\epsilon}_{\mathrm{W}}-P / 3 K_{\mathrm{G}}
$$

where $\dot{\epsilon}_{\mathrm{W}}$ is the linear strain rate of the wet gel during syneresis (when the gel is so small that no pressure develops). The function $K_{\mathbf{G}}$ is the effective bulk modulus of the gel ; it is proportional to the viscosity, and increases as the porosity decreases. Equation ( 5 ) shows that the contraction rate of the gel increases with the tensile pressure in the liquid, and is inversely proportional to the viscosity $(\eta)$ of the solid phase ( since $\left.K_{\mathrm{G}} \propto \eta\right)$. Stresses in a gel body develop when the strain rate $\dot{\epsilon}_{\mathrm{f}}$ varies through its thickness, so the greater the variation in $P$, the greater the stress in the gel. The pressure gradient (and consequently the tensile stress in the body) increases as the permeability $(D)$ decreases and the evaporation rate increases.

The pressure distribution depends on the shape of the gel. For example, when liquid flows from the interior of a cylinder of gel, it enters a volume that increases as $r^{2}$. This makes outward flow easier and the pressure in the liquid more uniform in a cylinder than in a plate. If liquid cannot escape from the interior of a gel, then the exterior contracts faster than the interior, and tensile stresses appear at the exterior surface. Therefore, the stresses will be greater in a plate than in a cylinder, and will increase with the size of the body.

Thus, the stress is proportional to the evaporation rate and the size of the body, and inversely proportional to the permeability and the bulk modulus $\left(K_{\mathrm{G}}\right)$. This explains why slower drying prevents cracking. It may also explain the effect of DCCA, which increase the pore size (increasing $D$ ) and the hardness (related to $K_{\mathrm{G}}$ ) of the gel. The stress is shape-dependent, decreasing in the order : plate $>$ cylinder $>$ sphere.

\subsection{Theory for elastic gels}

As the gel shrinks it becomes stiffer, because of the formation of new crosslinks, as well as the closer packing of the clusters. If the solid phase is elastic, rather than viscous, the pressure in the 


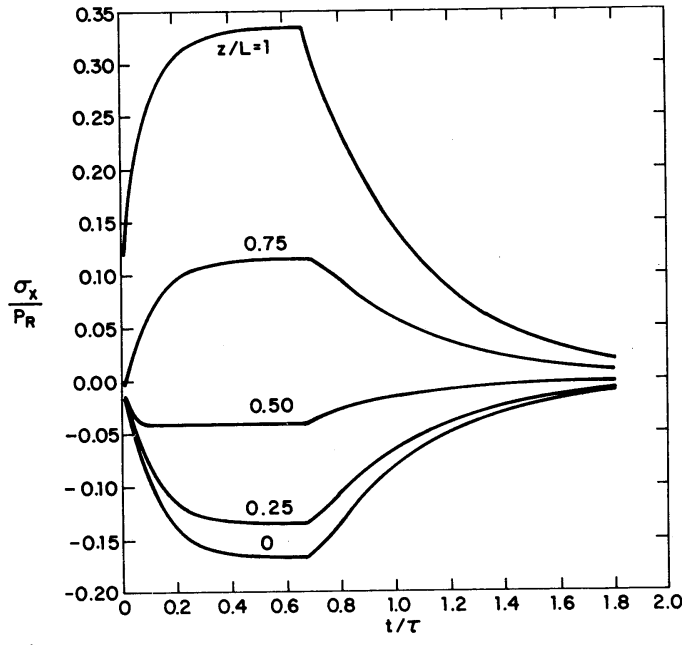

Fig. 12. Stress in plate of elastic gel drying by evaporation from both faces; $P_{\mathrm{R}}$ is maximum capillary pressure in liquid ; $\tau=L^{2} \eta_{\mathrm{L}} / D K ; z / L=1$ at the surface and 0 at the midplane (from Scherer ${ }^{122)}$ ).

liquid is governed by a differential equation that is equivalent to the diffusion equation, so solutions for many cases of interest are available in the literature ${ }^{123), 124)}$. If the gel is elastic when the liquid-vapor meniscus develops, then a transient tensile stress develops. Tensile stress develops in the liquid at the exterior, causing a contraction of the solid network; as the pressure in the interior rises, the contraction becomes uniform throughout the body, and the stress decays to zero. This is illustrated in Fig. 12, which shows the stress in the gel as a function of time at several points in a plate that is drying by evaporation from both sides. The stress is normalized by the capillary pressure, $P_{\mathrm{R}}$, and the time is normalized by $\tau=L^{2} \eta_{\mathrm{L}} / D K$

where $K$ is the bulk modulus of the elastic gel. It is during this stage, when the meniscus enters the gel, that fracture is most likely. The analysis shows that the magnitude of the stress is proportional to the evaporation rate, just as in the viscous case, so slow drying reduces the risk of fracture of the gel.

As the meniscus enters the gel, the vapor pressure, $p$, of the liquid drops as the tensile pressure in the liquid rises, according to

$$
p=p_{0} \exp \left(-P V_{\mathrm{m}} / R T\right)
$$

where $p_{0}$ is the equilibrium vapor pressure (when the liquid-vapor interface is flat), $V_{\mathrm{m}}$ is the molar volume, $R$ is the ideal gas constant, and $T$ is temperature. The maximum pressure in the liquid is $P_{\mathrm{R}}$, and this can be large enough to reduce $p$ by about a factor of 2. This effect cannot account for the sudden decrease in evaporation rate observed by Dwivedi ${ }^{125}$ when the meniscus entered an alumina gel. He attributed it to slow diffusion of vapor through the pores.

Once the meniscus has entered the gel and the stress has decayed (as at $t / \tau>2$ in Fig. 12), the solid phase is uniformly contracted under the influence of the capillary pressure $P_{\mathrm{R}}$. As the liquid-vapor meniscus moves into the gel, the dry exterior region is freed of that pressure, so it expands. This is probably the phenomenon observed by Kawaguchi et al. ${ }^{126)}$, who found a $1.2 \%$ expansion of their gel in the last stage of drying.

The drying model predicts that a gradient of porosity will be present in the dry gel ; the sign and magnitude of the variation depend on the value of the parameter $\alpha$ and on the way $\eta$ changes as the gel dries. Unfortunately, there are no data on which to base a prediction. However, there is experimental evidence ${ }^{126)}$ for lower density (as well as more residual organic material) at the exterior surface of a dried gel. That gel was found to exhibit birefringence, indicating residual stress. A porosity gradient could produce such stress, since an elastic contraction is caused by the surface energy of a porous body ${ }^{127}$; if the more porous exterior shrinks more than the body as a whole, tensile stress will develop in the exterior, as observed. It is not clear whether this explanation applies to the case described by Kawaguchi et al. ${ }^{126)}$, because they found that the sign of the birefringence reversed upon heating to $350^{\circ} \mathrm{C}$. It is possible that they observed form birefringence, caused by structural anisotropy, that changed when the organics burned out.

It has been observed ${ }^{109)}$ that very slow drying produces gels with high porosity. This may result from aging during drying, causing the viscosity of the gel to become so high that relatively little contraction can occur. The porosity of the gel also increases with the gelling temperature ${ }^{77)}$ and with the use of the DCCA formamide ${ }^{89}$, possibly because the aging is accelerated. Higher $\mathrm{pH}$ produces a more densely crosslinked, stiffer network, and leads to increased porosity ${ }^{10)}$.

In the model presented above it is assumed that the liquid-vapor interface moves uniformly into the gel. Shaw ${ }^{128)}$ has shown that the drying front can become fractal, with the dried region extending far ahead of the nominal interface. This 
phenomenon can be observed during the drying of porous glass, such as $\mathrm{VYCOR}^{\circledR}$, which is clear when fully saturated or fully dry, but which becomes opaque during drying : the irregular dry regions are large enough to scatter light, so the partially dried piece looks white. Most alkoxidederived gels remain clear during drying, so there may be a uniform drying front ; if so, it probably reflects the relatively narrow distribution of pore sizes in such materials.

Another factor that is not considered in the model is diffusion within the pore liquid. If the pores contain a mixture of liquids that differ significantly in vapor pressure, as when a DCCA is present, the more volatile liquid will diffuse to the surface and evaporate. If the diffusion coefficient is high, the evaporative flux may be supplied with a small concentration gradient within the gel. That means that contraction of the gel can occur more uniformly than when a single component is present and flow requires a pressure gradient. The relative importance of diffusion can be estimated as follows. Suppose that the flux $(J)$ of alcohol to the surface of one gel is provided by chemical diffusion; the flux is approximately

$$
J \approx-D_{\mathrm{c}} V_{\mathrm{m}} \Delta C / L
$$

where $D_{\mathrm{c}}$ is the diffusion coefficient, $V_{\mathrm{m}}$ is the molar volume, and $\Delta C / L$ is the concentration gradient from the center to the surface. Let another gel of the same size have the same flux, but assume that only one liquid is present, so the flow is produced by a pressure gradient; then,

$$
J \approx\left(D / \eta_{\mathrm{L}}\right) \Delta P / L
$$

If the stress in the first gel is $\sigma_{\mathrm{D}}$ and the stress in the second is $\sigma_{\mathrm{F}}$, then it can be shown that

$$
\sigma_{\mathrm{D}} / \sigma_{\mathrm{F}} \approx K D / D_{\mathrm{c}} \eta_{\mathrm{L}}
$$

Using typical values for a wet gel $\left(K \approx 10^{7} \mathrm{~Pa}\right.$, $\left.D \approx 10^{-15} \mathrm{~cm}^{2}, \quad D_{\mathrm{c}} \approx 10^{-5} \mathrm{~cm}^{2} / \mathrm{s}, \quad \eta_{\mathrm{L}} \approx 10^{-3} \mathrm{~Pa} \cdot \mathrm{s}\right)$, the ratio is near unity; the lower the permeability and the faster the diffusion coefficient, the more advantageous it is to use a mixture of liquids.

\subsection{Aerogels}

The danger of cracking during drying can be avoided if the gel is subjected to hypercritical drying. The gel is heated above the critical temperature and pressure of the liquid phase, at which point there is no interface between liquid and vapor. Therefore, there is no difference between $\gamma_{\mathrm{SL}}$ and $\gamma_{\mathrm{Sv}}$, so the capillary pressure in the liquid, $P_{\mathrm{R}}$, is zero. The gel dries without shrinking, so the dried body has the same volume as the starting solution. This technique was invented by Kistler ${ }^{129), 130)}$, and has been used to prepare bodies with high surface area for use as catalytic substrates. The preparation and properties of inorganic oxide aerogels have been reviewed by Teichner et al. ${ }^{131)}$; the proceedings of a recent conference devoted to aerogels are presented in Ref.132). Until recently, hypercritical drying was used to prepare powders, but it is now used to make pieces as large as tens of centimeters. ${ }^{114), 133)}$. The gel is placed in an autoclave with excess solvent and carefully heated above the critical temperature, $T_{\mathrm{c}}$. The purpose of the extra liquid is to provide a high partial pressure of solvent to prevent drying of the gel at temperatures below $T_{\mathrm{c}}$. Van Lierop et al. ${ }^{134)}$ have shown that the same purpose is served by a high pressure of inert gas (e.g. 80 bars of nitrogen); at these high pressures, nitrogen evidently reduces the vapor pressure of the alcohol. Once the critical conditions have been surpassed, the pressure is vented while holding the temperature above $T_{c}$. The entire drying process is thus reduced from days or weeks to hours. Tewari et al. ${ }^{135)}$ have demonstrated another method of hypercritical drying: the wet gel is rinsed in liquid $\mathrm{CO}_{2}$ (under pressure) until all of the solvent is replaced, then the $\mathrm{CO}_{2}$ is removed above its critical point. The advantage of this procedure is that $T_{\mathrm{c}}=31^{\circ} \mathrm{C}$ and $P_{\mathrm{c}}=73$ bars for $\mathrm{CO}_{2}$, versus $243^{\circ} \mathrm{C}$ and 63 bars for ethanol or $240^{\circ} \mathrm{C}$ and 78.5 bars for methanol; therefore simpler equipment can be used.

Silica aerogels are transparent and can be prepared $^{136)}$ with densities as low as $0.03 \mathrm{~g} / \mathrm{cm}^{3}$. Schaefer et al. ${ }^{137}$ have used SAXS to analyze the structure of an aerogel, and found that it consists of dense particles (Porod slope $=-4$ ) with radius on the order of $1.2 \mathrm{~nm}$; the particles are arranged in chains (Porod slope $=-2$ ), and the structure is uniform on a scale larger than $8.5 \mathrm{~nm}$. Such a structure was observed directly by TEM by Mulder et al. ${ }^{136)}$, who show a beautiful stereopair illustrating the 3-dimensional arrangement of the particles.

\subsection{Structure of dried gels}

The pores in gels are too small to be measured by mercury penetration porosimetry, so nitrogen adsorption is commonly used (see Ref. 138) for a lucid description of pore size measurements by these techniques). Typically, the adsorption and desorption isotherms indicate different mean pore 
sizes, which is interpreted to mean that "inkbottle" pores are present, with entrances that are smaller than the main pore cavity. In some cases (e.g. Ref.66)), when all of the pores have diameters smaller than $\sim 2 \mathrm{~nm}$, no hysteresis is observed, and the ususal BET equation does not give the correct surface area. A disturbing observation, recently reported by Wallace and $\mathrm{Hench}^{139)}$, is that different surface areas and pore size distributions are obtained on the same sample using adsorption equipment sold by different manufacturers.

Nogami and Moriya ${ }^{86)}$ showed that silica gels produced using ammonium hydroxide as a catalyst have a granular appearance in the TEM, but the structure of an acid-catalyzed gel was too fine to see. Nitrogen adsorption analysis of the latter indicated a bimodal pore size distribution, consisting of 2 and $7 \mathrm{~nm}$ pore diameters. Yamane and $\mathrm{Okano}^{77)}$ found a similar size distribution, and showed that the proportion of larger pores increased with the temperature of gelation. As mentioned earlier, the bimodal distribution has been attributed ${ }^{75,76)}$ to aggregation of clusters during gelation, producing large pores between, and small pores within, the clusters. The difference between acid- and base-catalyzed gels is illustrated in Fig. 13. Brinker and Scherer ${ }^{140)}$ argue that the lower crosslink density at low $\mathrm{pH}$ allows the gel to collapse to a denser structure during drying. The higher crosslink density in the basic system makes the gel more rigid, so that it is better able to resist the capillary forces and shrinks less during drying. Note that aging under basic conditions converts the acid-catalyzed gel into a coarser structure ${ }^{140}$, resembling that produced in a base-catalyzed system. This results ${ }^{53}$ from dissolution of silica from regions of high positive curvature and precipitation in regions of negative curvature; the process is rapid at high $\mathrm{pH}$, because of the enhanced solubility of silica. The pore size distribution can also be influenced by chemicals added to the original sol. Hench ${ }^{89}$ reports that narrower distributions are achieved when a DCCA is added; the mean pore size is made smaller by oxalic acid and larger by formamide.

By measuring the pore volume and the bulk density of a gel, the skeletal density (i.e. the density of the solid phase), $\rho_{\mathrm{s}}$, can be calculated. Brinker and Scherer ${ }^{65}$ point out that $\rho_{\mathrm{s}}$ is generally found to be lower than the density of the

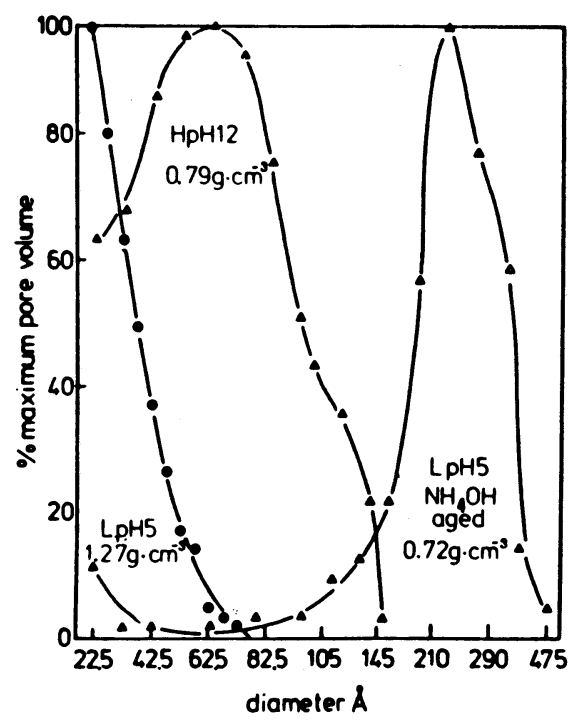

Fig. 13. Pore size distributions (normalized to $100 \%$ at the mode pore diameter) and bulk densities of desiccated gels $\mathrm{LpH} 5, \mathrm{HpH} 12$, and $\mathrm{LpH} 5$ aged 1 week at $50^{\circ} \mathrm{C}$ in $3 \mathrm{M} \mathrm{NH}_{4} \mathrm{OH}$ prior to desiccation. For gelation conditions see Table 2 (from Brinker and Scherer $\left.{ }^{140)}\right)$. Copyright ${ }^{(} 1984$ by John Wiley \& Sons, Inc. Reprinted by permission of the publisher.

Table 2. Matrix of gelation conditions and measured bulk densities of desiccated gels ${ }^{\text {a) }}$. Copyright $\left.{ }^{(}\right) 1984$ by John Wiley \& Sons, Inc. Reprinted by permission of the publisher.

\begin{tabular}{clll}
\hline $\mathrm{H}_{2} \mathrm{O}$ & 2.5 & 6.8 & 9.2 \\
\hline \multirow{2}{*}{5} & & & \\
& LpH5 & MpH5 & \\
\multirow{2}{*}{8} & 1.27 & 1.17 & \\
& LpH8 & MpH8 & HpH8 \\
12 & 1.28 & 1.28 & 0.75 \\
& LpH12 & MpH12 & HpH12 \\
& & 1.15 & 0.79
\end{tabular}

a) $\mathrm{LpH}, \mathrm{MpH}$ and $\mathrm{HpH}$ refer to low, medium and high $\mathrm{pH}$, respectively. The numbers 5,8 , and 12 refer to the water addition in moles of water/mole alkoxides. From Brinker and Scherer ${ }^{140)}$.

corresponding melted glass, and attribute this fact to the low crosslink density at the time of gelation. Wenzel ${ }^{141)}$ argued against a similar claim by Brinker and Mukherjee ${ }^{84)}$, suggesting instead that the low $\rho_{\mathrm{s}}$ indicates the existence of isolated pores, inaccessible to the adsorbate. There are two strong arguments against isolated porosity. First, as shown in the next section, the skeletal density increases at low temperatures (long before the onset of viscous sintering); if those pores are sintering, they must be at least an order of magnitude smaller than the open pores, which means that they are of molecular dimensions. Second, the dried gel has a very high thermal expansion coefficient $\left(280 \times 10^{-7}{ }^{\circ} \mathrm{C}^{-1}\right.$ for silica 
gel versus $5 \times 10^{-7}{ }^{\circ} \mathrm{C}^{-1}$ for fused silica $)^{126)}$ and low elastic modulus ${ }^{142)}$, indicating a high concentration of nonbridging oxygen bonds; isolated pores would not have such large effects on either property. After heating to $\sim 500^{\circ} \mathrm{C}$ the thermal expansion returns to the value characteristic of silica.

\section{Heat treatment before sintering}

Dried gels contain chemisorbed hydroxyl and alkoxy groups, in addition to physically adsorbed alcohol and water, which must be removed during heating. The greater the water/alkoxide ratio during gel preparation, the smaller the amount of retained organics in the gel $^{74,84)}$, as shown in Fig. 14. A higher water content leads to a smaller weight loss at low temperatures (where organics are oxidized) and a larger loss (of hydroxyls) at higher temperatures ${ }^{82)}$. A typical thermogram is shown in Fig. 15. The endotherm below $200^{\circ} \mathrm{C}$ is from desorption of water and alcohol, and the

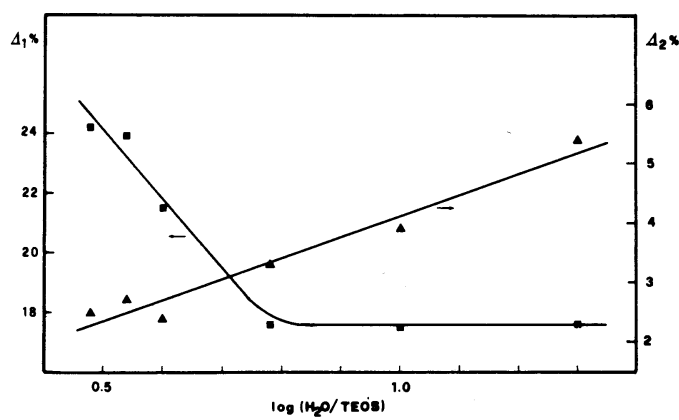

Fig. 14. Percentage weight losses in the temperature ranges $150^{\circ}-600^{\circ} \mathrm{C}\left(\Delta_{1}\right)$ and $600^{\circ}-1100^{\circ} \mathrm{C}\left(\Delta_{2}\right)$ versus $\log \left(\mathrm{H}_{2} \mathrm{O} / \mathrm{TEOS}\right)$, as obtained by thermogravimetric analysis (from Gottardi et al. ${ }^{82)}$ ).
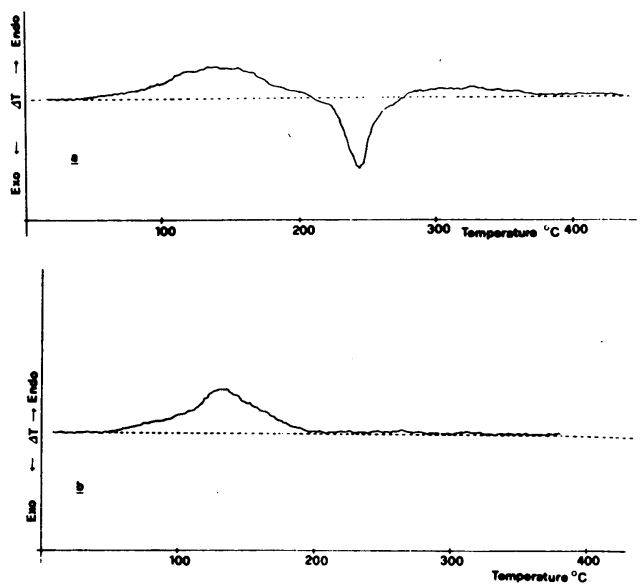

Fig. 15. Thermal analysis of a gel dried for $10 \mathrm{~h}$ at $55^{\circ} \mathrm{C}$ : (a) DTA diagram in air ; (b) DTA diagram under nitrogen (from Carturan et al. ${ }^{143)}$ ). exotherm between $200^{\circ}$ and $300^{\circ} \mathrm{C}$ represents oxidation of residual organics ; the latter peak is not observed when the gel is heated in nitrogen ${ }^{143}$. The surface area increases when the organics burn off, opening new micropores ${ }^{11), 144}$. The evaporation and oxidation reactions evolve a large volume of gas that must diffuse out through the very small pore network. It is necessary to heat the gel slowly $\left(<1^{\circ} \mathrm{C} / \mathrm{min}\right)^{11,77), 145)}$ to avoid pressure build-up inside the gel that can cause cracking. Substantial amounts of gas are produced up to $\sim 500^{\circ} \mathrm{C}$, and some evolves at temperatures up to $\sim 800^{\circ} \mathrm{C}$. This is a serious problem in gel compositions with glass transition temperatures below $\sim 600^{\circ} \mathrm{C}$, because sintering begins before the reactions are complete, and bloating and cracking of the gel occur ${ }^{13)}$. Even in silica gel, Yamane and $\mathrm{Okano}^{77)}$ recommend that the gel contain a large fraction of pores larger than $5 \mathrm{~nm}$ in diameter, which will remain open until $800^{\circ} \mathrm{C}$.

Removal of hydroxyls is particularly important if the gel is used to prepare an optical waveguide fiber, so Susa et al. ${ }^{146), 147)}$ exposed their silica gel to chlorine gas above $800^{\circ} \mathrm{C}$. This replaces the $\mathrm{SiOH}$ with $\mathrm{SiCl}$, and leads to reboil of $\mathrm{Cl}_{2}$ at higher temperatures; therefore, it was necessary to follow the chlorine treatment with an oxygen treatment at $1100^{\circ} \mathrm{C}$ or above ${ }^{147)}$. Rabinovich et al. ${ }^{148)}$ found that it was difficult to prevent $\mathrm{Cl}_{2}$ reboil by that method, so they used fluorine in the form of $\mathrm{NH}_{4} \mathrm{~F}$ or $\mathrm{SiF}_{4}$ to remove hydroxyl. The $\mathrm{SiF}$ bond is so strong that it does not dissociate at higher temperatures, so there is no reboil. Phalippou et al. ${ }^{149}$ found that the high hydroxyl content of their aerogel caused reboil when the gel was heated above the sintering temperature; the problem was eliminated by dehydrating with a chlorine treatment. In this case the residual $\mathrm{Cl}$ content was not high enough to cause reboil of $\mathrm{Cl}_{2}$.

The chemical and structural changes occurring during heating of a gel have been studied in detail by Brinker and coworkers ${ }^{140), 144), 150), 151)}$, and the following discussion is based on their work. Three characteristic regions of temperature are observed in the shrinkage behavior of a gel: in region $\mathrm{I}\left(<200^{\circ} \mathrm{C}\right)$ there is substantial weight loss with little shrinkage; in region II $\left(200^{\circ} \mathrm{C}<T\right.$ $<600^{\circ} \mathrm{C}$ ) both weight loss and shrinkage are great; in region III $\left(>600^{\circ} \mathrm{C}\right)$ shrinkage occurs principally by sintering, with very little weight loss. This is illustrated in Fig. 16 for the case of 


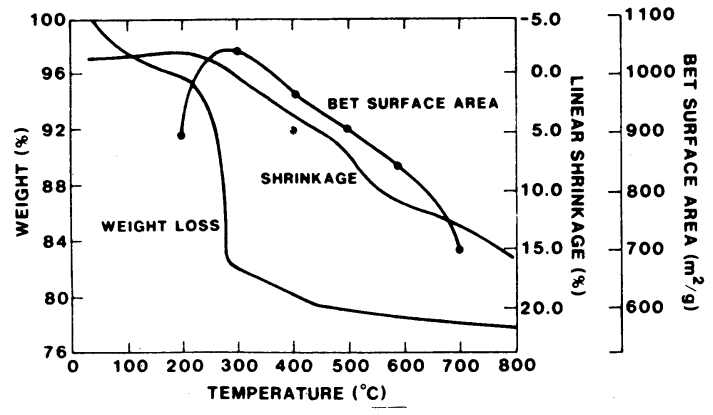

( a )

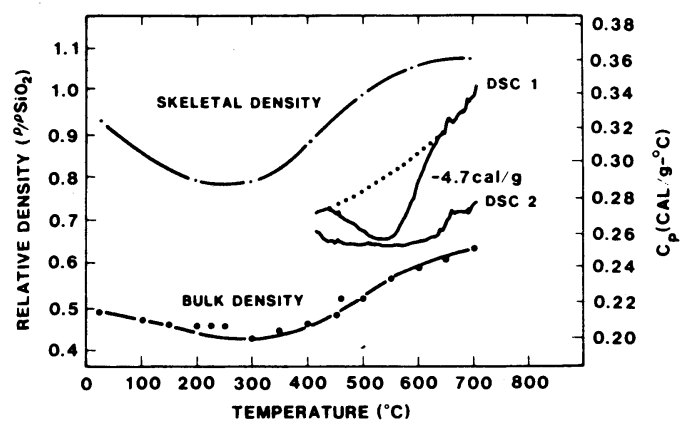

( b )

Fig. 16. (a) Weight loss, shrinkage and BET surface area for A 2 heated at $2^{\circ} \mathrm{C} / \mathrm{min}$ in air. (b) Calculated bulk density and skeletal densities and first and second DSC scans, DSC-1 and DSC-2, respectively, for A 2. Relative densities above 1.0 result from errors associated with the measurements of pore volume and bulk density (from Brinker et al. ${ }^{144)}$ ).

an acid-catalyzed silica gel having a relatively low crosslink density. The gel actually expands up to $200^{\circ} \mathrm{C}$, because, as mentioned earlier, the larger number of nonbridging oxygens gives the gel a high thermal expansion coefficient; the concurrent weight loss is large. Between $200^{\circ}$ and $300^{\circ} \mathrm{C}$ there is a dramatic weight loss and an increase in surface area as the organics burn out, and the gel begins to contract. The skeletal density $\rho_{\mathrm{S}}$ is initially less than that of silica $\left(2.2 \mathrm{~g} / \mathrm{cm}^{3}\right)$ and decreases further as the organics burn out. Between $300^{\circ}$ and $400^{\circ} \mathrm{C}$ the densification of the skeleton causes shrinkage and the weight loss suggests that shrinkage is produced by condensation reactions. The skeleton increases in density rapidly between $400^{\circ}$ and $600^{\circ} \mathrm{C}$, and there is a sudden shrinkage with no accompanying weight loss; the differential scanning calorimeter (DSC) shows an exotherm in that temperature range. This contraction is attributed to structural relaxation, i. e. structural rearrangement with no change in composition. The condensation reactions at lower temperatures

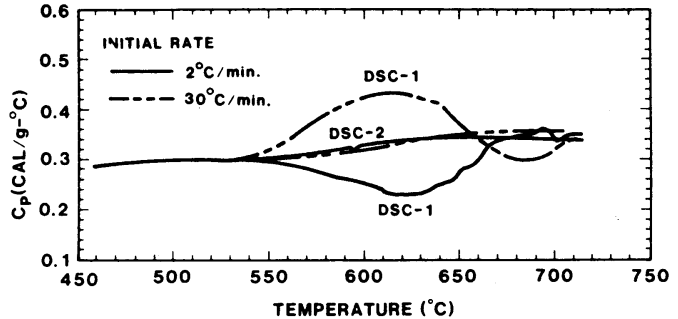

(a)

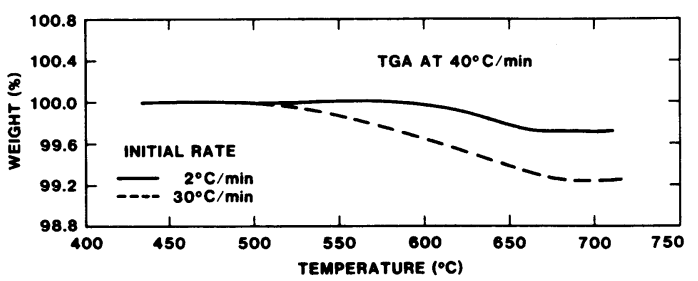

( b )

Fig. 17. (a) Initial and repeat DSC scans, DSC-1 and DSC-2, for multicomponent gel samples initially heated to $525^{\circ} \mathrm{C}$ at $2^{\circ}$ and $30^{\circ} \mathrm{C} / \mathrm{min}$. (b) Weight loss at $40^{\circ} \mathrm{C} / \mathrm{min}$ for same samples as in Fig. 17(a) (from Brinker et al. ${ }^{144)}$ ).

produce energetic structures, such as 3-membered rings (containing $3 \mathrm{Si}$ and 30 atoms), that convert exothermically into more stable structures (e.g. larger rings) at higher temperatures.

Several studies ${ }^{82,144), 152)}$ using Raman spectroscopy have shown that a defect band (called $\left.D_{2}\right)$ is much larger in silica gels than in fused silica, and that it decreases upon sintering. The strength of $D_{2}$ is inversely related to that of the $\mathrm{SiOH}$ absorption, suggesting that the structure responsible for $D_{2}$ results from a condensation reaction. Brinker et al. ${ }^{153)}$ have now shown unambiguously that the defect structure is a strained 3-membered ring, and that it results from condensation of silanols. The formation of such rings is endothermic, as shown in Fig. 17. The more rapidly heated gel exhibits an endotherm as condensation reactions produce strained rings, then an exotherm as the rings rearrange above $650^{\circ} \mathrm{C}$; the endotherm coincides with a loss of weight. The sample heated at $2^{\circ} \mathrm{C} / \mathrm{min}$ has a small hydroxyl content, so the DSC shows only an exotherm; the concurrent weight loss is small. Puyane et al. ${ }^{\text {}}{ }^{8)}$ observed such an exotherm, and attributed it to the high fictive temperature of the gel. That is, the gel is analogous to a glass quenched rapidly from a high temperature, in that it has a low skeletal density. They showed that the same thermogram was obtained upon reheating of a rapidly quenched glass as structural 
relaxation occurred. The exotherm in Fig. 17 probably contains contributions from structural relaxation, as well as loss of surface area (which contributes energy equal to $\gamma_{\mathrm{sv}} S$ ).

Brinker et al. ${ }^{151)}$ compared the densification behavior of gels produced from TEOS by acid or base catalysis, and a colloidal gel made from Aerosil ${ }^{\circledR}{ }^{14)}$, as shown in Fig. 18. In the colloidal gel, the silica particles are fully dense, not polymeric, and have hydroxyl groups only on the surface. The acid-catalyzed gel, called A 2, is the same one shown in Figs. 16 and 17. It loses much more weight than the base-catalyzed gel (B 2), because it was prepared with a relatively small water content $\left(\mathrm{H}_{2} \mathrm{O} / \mathrm{TEOS}=5 / 1\right)$, and was apparently reesterified during drying. The more densely crosslinked B2 gel has a smaller thermal expansion coefficient at low temperatures, and contracts less in region II , because of its higher skeletal density. The colloidal gel shows no significant change until it is hot enough to sinter; faster heating delays sintering to a higher
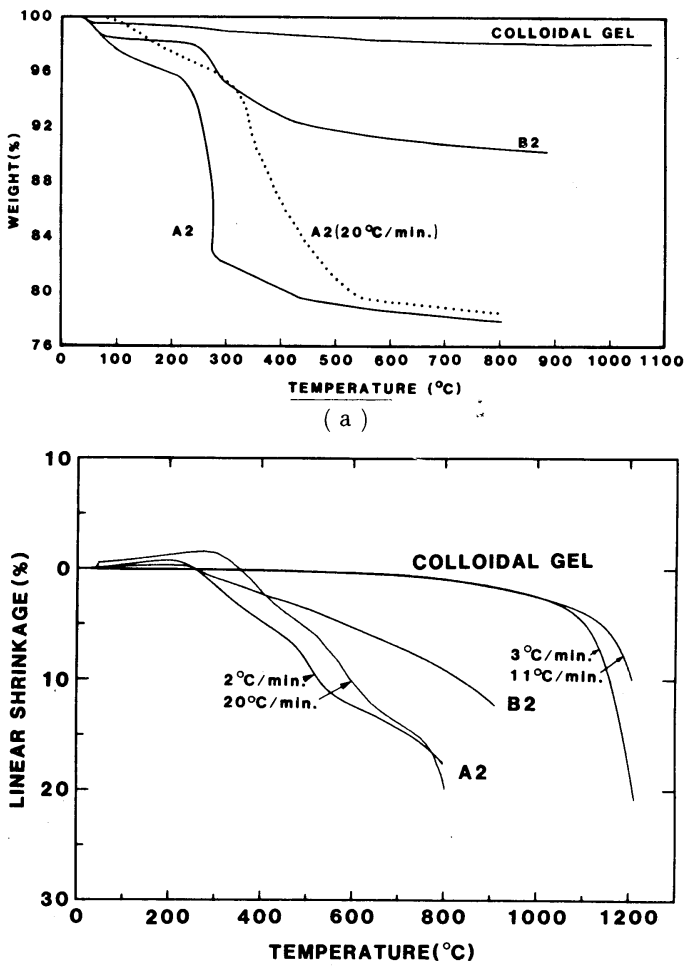

( b )

Fig. 18. (a) Percent of original weight for colloidal gel, B 2 and $\mathrm{A} 2$ heated at $2^{\circ} \mathrm{C} / \mathrm{min}$. Dotted line equals A 2 heated at $20^{\circ} \mathrm{C} / \mathrm{min}$. (b) Linear thermal shrinkage at constant heating rates for gels in Fig. 18(a) (from Brinker et al. $\left.{ }^{151)}\right)$. Copyright 1984 by Elsevier Science Publishing Co., Inc. Reprinted by permission of the publisher.

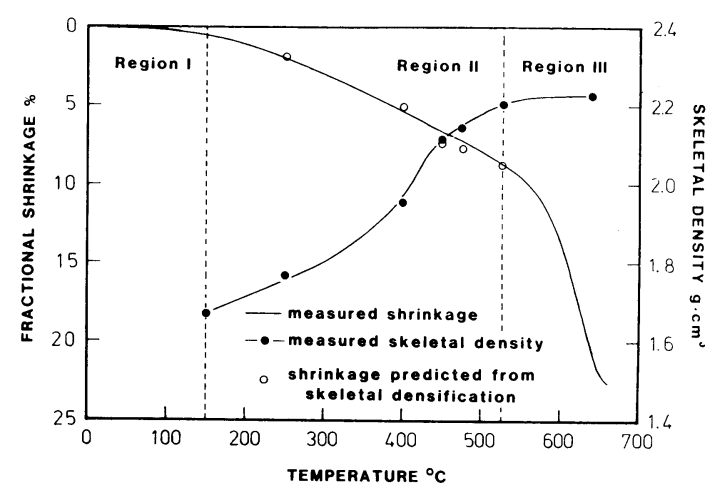

Fig. 19. Linear shrinkage and skeletal density measured for heating rate of $2^{\circ} \mathrm{C} / \mathrm{min}$. Open circles represent the shrinkage above $150^{\circ} \mathrm{C}$ which can be accounted for by the increased skeletal density (from Brinker et al. ${ }^{150)}$ ).

temperature. Faster heating of A2 delays the shrinkage in region II, but leaves the gel with a higher hydroxyl content and a less relaxed structure; this accelerates the rapid contraction during sintering $\left(\sim 800^{\circ} \mathrm{C}\right)$.

The same phenomena are seen in multicomponent gels. Brinker and Scherer ${ }^{140)}$ prepared a gel with the approximate composition (by weight) $77 \mathrm{SiO}_{2} \cdot 11 \mathrm{~B}_{2} \mathrm{O}_{3} \cdot 9 \mathrm{Al}_{2} \mathrm{O}_{3} \cdot 3 \mathrm{BaO}$ using a range of $\mathrm{pH}$ and water/alkoxide ratios. A gel made at a lower $\mathrm{pH}$ and with less water exhibits more change in skeletal density, because of the lower crosslink density of the gel. In another study, Brinker et al. ${ }^{150)}$ prepared a five component gel $\left(66 \mathrm{SiO}_{2} \cdot 18 \mathrm{~B}_{2} \mathrm{O}_{3} \cdot 7 \mathrm{Al}_{2} \mathrm{O}_{3} \cdot 6 \mathrm{Na}_{2} \mathrm{O} \cdot 3 \mathrm{BaO}\right)$ and showed that the skeletal densification in region II could quantitatively account for the observed shrinkage (see Fig. 19).

In the next section, the kinetics of sintering are examined. The structural and chemical changes that dominate regions I and II also influence region III.

\section{Sintering}

Several reviews of the sintering of gels have recently been published ${ }^{20,154), 155)}$, so only the essential features are discussed here.

\subsection{Xerogels}

A porous body tends to contract (sinter) to reduce its interfacial area; in an amorphous material, shrinkage of the pores occurs by viscous flow of the solid phase. The rate of viscous sintering is calculated by equating the energy gained by decreasing the surface area to the energy dissipated in viscous flow as the body contracts. The 
large surface area of a gel provides such a strong driving force that sintering begins near the glass transition temperature $\left(T_{\mathrm{g}}\right)$, where the viscosity is $\sim 10^{12} \mathrm{~Pa} \cdot \mathrm{s}$. Models of viscous sintering have been developed using a variety of assumptions about the microstructure ${ }^{156)-158)}$, but all indicate that the contraction rate $\dot{\epsilon}$ is given by ${ }^{159)}$

$$
\dot{\epsilon} \propto \gamma_{\mathrm{sv}} n^{1 / 3} / \eta
$$

where $n$ is the number of pores per unit volume. For a given relative density, $n$ increases as the pore size decreases; thus $\dot{\epsilon}$ is fast when the pores are small and the viscosity is low. The smaller the pores, the higher the viscosity at which an appreciable contraction rate is observed. If a distribution of pore sizes is present, the smaller pores are expected to contract first, and this is commonly observed ${ }^{77), 86), 160)}$.

The theoretical relationship between relative density and time is shown in Fig. 20. This curve is based on a model ${ }^{158}$ ) that represents the microstructure as a network of solid cylinders enclosing a continuous pore space. The reduced time is $K t$, where $K=\gamma_{\mathrm{sv}} n^{1 / 3} / \eta$ and $n=l_{0}^{-3} \rho_{\mathrm{s}} / \rho_{0} ; l_{0}$ is the initial edge length of a unit cell of the structure and $\rho_{0} / \rho_{\mathrm{s}}$ is the initial relative density. To compare experimental data with the model, one measures the density of a sintered sample and finds the reduced time from the theoretical curve corresponding to that density. A plot of reduced time against the actual sintering time should be a straight line with a slope of $K$, as in Fig. $20 \mathrm{~B}$. Brinker and Scherer ${ }^{140)}$ showed that the model is not obeyed at the beginning of sintering, as indicated in Fig. 21. The viscosity of the gel appears to increase for a long time ( $~ 8$ hours, in Fig. 21), then become constant. By determining $K$ as a function of time, they showed that the viscosity increased by as much as two orders of magnitude during an isothermal sintering ex-
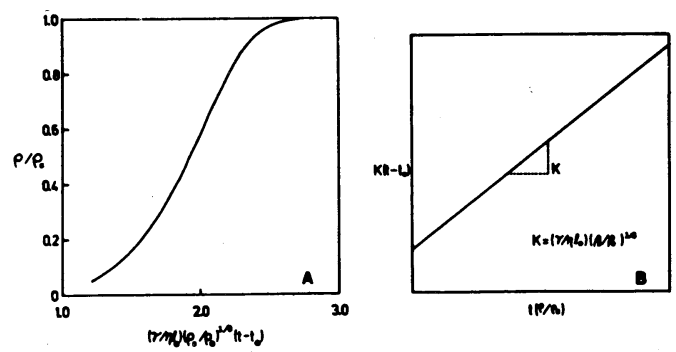

Fig. 20. Plots of (A) density versus reduced time and (B) reduced time versus experimental time predicted by cylinder model ${ }^{158)}$ (from Brinker and Scherer ${ }^{140)}$ ). Copyright $^{\complement} 1984$ by John Wiley \& Sons, Inc. Reprinted by permission of the publisher.

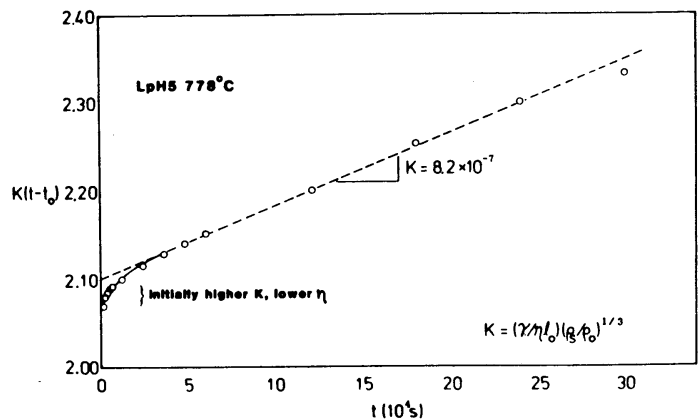

Fig. 21. Experimentally determined $K\left(t-t_{0}\right)$ versus time plots at $778^{\circ} \mathrm{C}$ (from Brinker and Scherer ${ }^{140)}$ ). Copyright $^{\complement} 1984$ by John Wiley \& Sons, Inc. Reprinted by permission of the publisher.

periment. The increase is attributed to condensation reactions that eliminate nonbridging bonds and to structural relaxation. Figure 22 compares plots of $K^{-1}$ (a quantity proportional to $\eta$ ) versus density during isothermal sintering for three types of silica gel ${ }^{151)}$; these are the same gels as in Fig. 18. The samples were heated at $2^{\circ} \mathrm{C} / \mathrm{min}$ and held at the indicated temperatures. The acidcatalyzed gel (A 2) shows a continuous increase in $\eta$, the base-catalyzed gel (B 2) increases less and reaches a plateau, and the colloidal gel has essentially constant viscosity at a given temperature. These differences reflect the crosslink density in each gel. The colloidal gel consists of particles of dense silica glass, so it experiences no chemical or structural changes during sintering. In contrast, the A 2 gel is undergoing condensation reactions and structural relaxation at the same time as it sinters. In the B 2 gel, these changes are finished before complete densification, so the viscosity reaches a constant value. Note that the viscosity at the start of the isothermal hold is nearly independent of temperature. This results from the higher hydroxyl content retained at lower temperatures: as the gel is heated, the decrease in $\mathrm{OH}$ raises $\eta$ while the increase in temperature lowers $\eta$, and the effects nearly balance. Gallo and Klein ${ }^{161)}$ have made direct measurements of $\eta$ on porous gels using the beam-bending method. They found good agreement (i.e. within a factor of 2) with viscosities determined from sintering data, including the change in $\eta$ with time.

Gallo et al. ${ }^{162)}$ followed the hydroxyl content of a multicomponent gel during sintering. As shown in Fig. 23, at the highest temperature $\left(595^{\circ} \mathrm{C}\right)$ the viscosity increases more than 10 times with no change in $\mathrm{OH}$ content; this increase in $\eta$ is 


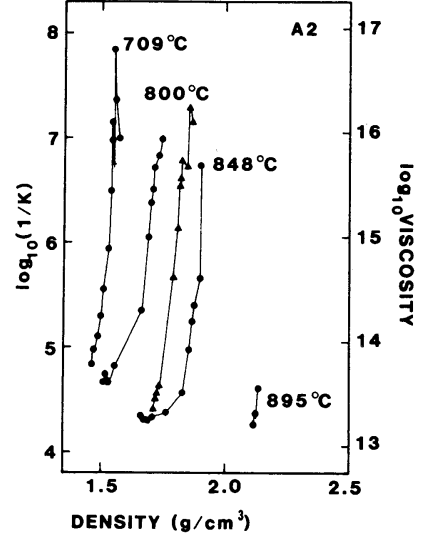

(a)

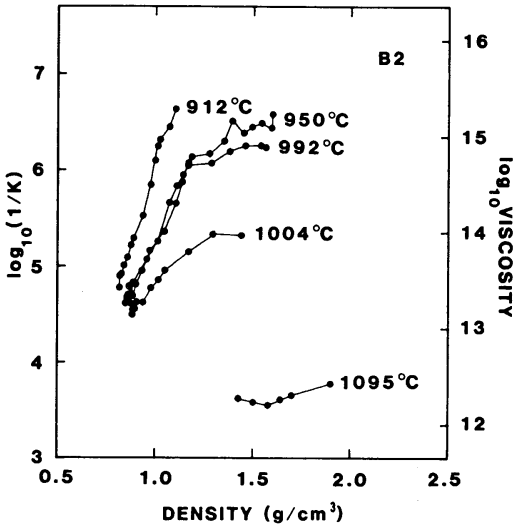

(b)

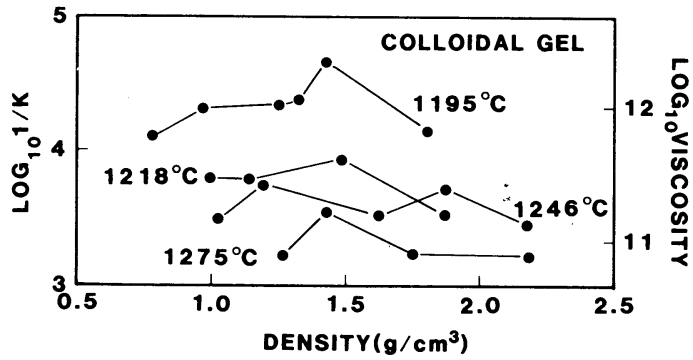

(c)

Fig. 22. Isothermal plots of $K^{-1}$ and viscosity versus density, after heating at $2^{\circ} \mathrm{C} / \mathrm{min}$, for (a) A $2\left(\boldsymbol{\Lambda}^{\prime} \mathrm{s}\right.$ denote an initial heating rate of $20^{\circ} \mathrm{C} / \mathrm{min}$ ), (b) $\mathrm{B} 2$, and (c) colloidal gel (from Brinker et al. ${ }^{151)}$ ). Copyright 1984 by Elsevier Science Publishing Co., Inc. Reprinted by permission of the publisher.

attributed entirely to structural relaxation. The other lines in Fig. 23 seem to be converging at low $\mathrm{OH}$, which would imply that the activation energy for viscous flow decreases with hydroxyl content; in fact, the opposite is true. The apparent convergence results from the increasing importance of structural relaxation, which tends to steepen the slopes of the lines. Gallo and Klein ${ }^{163)}$

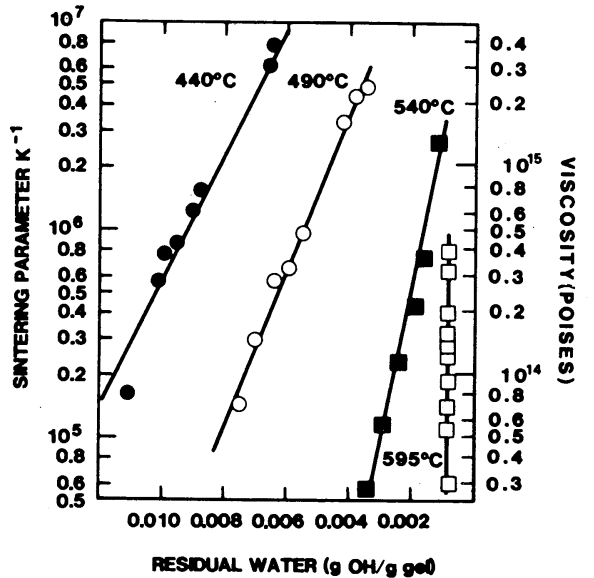

Fig. 23. Isothermal plots of $K^{-1}$ and viscosity versus residual $\mathrm{OH}$ content; found by analyzing sintering kinetics of multicomponent gel using cylinder mod$\mathrm{el}^{158)}$ (from Gallo et al. ${ }^{162)}$ ). Copyright 1984 by Elsevier Science Publishing Co., Inc. Reprinted by permission of the publisher.

subjected gels to various heating schedules and showed that different viscosities could be obtained at a given $\mathrm{OH}$ content, because of differences in the extent of structural relaxation.

It has been pointed out ${ }^{150), 162), 164)}$ that there is an optimum thermal history for sintering, since the viscosity increases with time and decreases with increasing temperature. During an isothermal hold the viscosity can rise so high that contraction stops long before densification is complete, so it is advantageous to continue heating during sintering. However, if the heating rate is too great, gases will be trapped in the pores and bloating or cracking may result. Gallo et al. ${ }^{162)}$ present isoviscosity plots that can be used to select a time-temperature program that preserves the viscosity at a constant value during sintering.

\subsection{Aerogels}

Phalippou et al. ${ }^{149)}$ found that silica aerogels densified rapidly at $\sim 1100^{\circ} \mathrm{C}$, but foamed at $~$ $1200^{\circ} \mathrm{C}$ because of their high ( $\left.3000 \mathrm{ppm}\right)$ hydroxyl content. They modeled bubble growth (reboil) by considering the relative pressures exerted by gas pressure and surface tension in a spherical pore, following the approach of Mackenzie and Shuttleworth ${ }^{157}$. A chlorine treatment was used to remove the $\mathrm{OH}$ and thereby prevent reboil. Since the viscosity of silica increases as the $\mathrm{OH}$ content decreases, the temperature of rapid sintering was raised by the chlorine treatment; however, all of the gels sintered at a viscosity of $\sim 10^{10} \mathrm{~Pa} \cdot \mathrm{s}$. Woignier et al. ${ }^{165)}$ prepared aerogels in the 
$\mathrm{SiO}_{2}-\mathrm{B}_{2} \mathrm{O}_{3}, \quad \mathrm{SiO}_{2}-\mathrm{P}_{2} \mathrm{O}_{5}, \quad \mathrm{SiO}_{2}-\mathrm{B}_{2} \mathrm{O}_{3}-\mathrm{P}_{2} \mathrm{O}_{5}$ systems. These gels sintered in the same range of viscosity as the silica aerogel; the phosphoruscontaining systems tended to crystallize.

Onorato ${ }^{166)}$ studied the sintering kinetics of silica aerogel and found good agreement with the cylinder model ${ }^{158)}$, as shown in Fig. 24. The densification rate was found to be atmospheredependent, because of the effect of atmospheric water on the viscosity of silica. However, $\eta$ was not time-dependent, because of the small amount of retained organic material or water in the structure. The model was extended to gels heated at a constant rate, and the calculated viscosities were in good agreement with the values found in isothermal experiments.

Mulder et al. ${ }^{167)}$ have directly examined the sintering of a silica aerogel by TEM. The coalescence of the particles is clearly seen.

\section{3 Sintering and crystallization}

It is often claimed that the sol-gel process produces glasses that are much more homogeneous than those made by conventional melting. A striking example is the preparation of $\mathrm{SrO}-\mathrm{SiO}_{2}$ glasses by Yamane and Kojima ${ }^{160)}$. This system has a stable two-liquid region extending well above $1800^{\circ} \mathrm{C}$, so melting a homogeneous glass would require very high temperatures, whereas the gels were sintered below $1000^{\circ} \mathrm{C}$. This was possible because the gel was homogeneous, and the kinetics of phase separation were slow enough at the sintering temperature. In contrast, in the

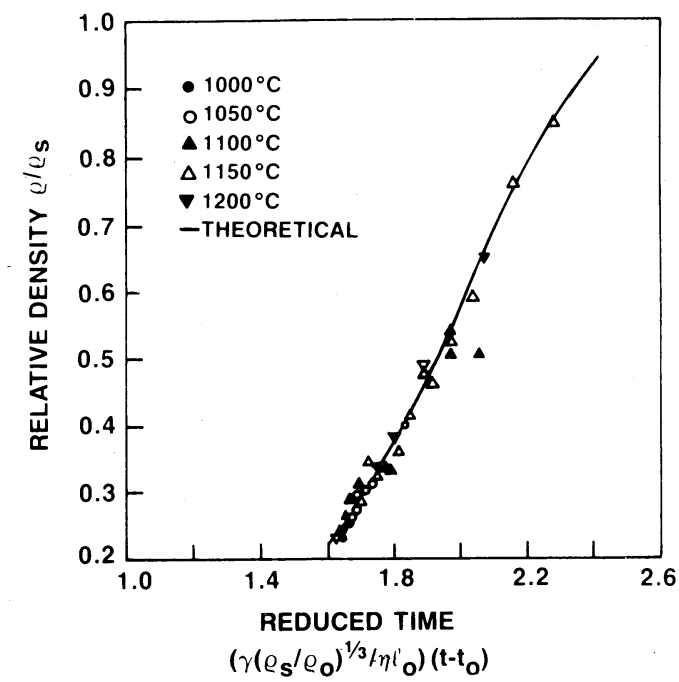

Fig. 24. Relative density versus reduced time for silica aerogel analyzed using cylinder model ${ }^{158}$ ) (from Onorato $\left.^{166)}\right)$.
$\mathrm{Na}_{2} \mathrm{O}-\mathrm{SiO}_{2}{ }^{81,168)}$ and $\mathrm{La}_{2} \mathrm{O}_{3}-\mathrm{SiO}_{2}{ }^{169)}$ systems, phase separation is so rapid that the gels become turbid before densification is complete. In other systems, crystallization interferes with sintering $^{170)}$ or even with drying ${ }^{171)}$ of the gel.

In principle it is possible to predict whether significant crystallization will occur during sintering by constructing a time-temperature-transformation curve, as suggested by Uhlmann ${ }^{172}$. Theoretical expressions for the rates of nucleation and crystallization are used to calculate the time required at any temperature to produce a given volume fraction (e.g. $10^{-6}$ ) of crystals. The solid curves shown in Fig. 25 were calculated in this way using the properties of wet and dry silica ${ }^{60)}$. The time to sinter a gel at each temperature can also be calculated; the dashed curves were obtained using the cylinder model ${ }^{158)}$. If the sintering curves lie to the left of the crystallization curves, then complete densification can be achieved before significant crystallization. In Fig. 25, good agreement is indicated between the calculated curves and the data of Sacks and Tseng ${ }^{173)}$. In general, unfortunately, calculation of the crystallization curves is subject to large errors, because the structure and hydroxyl content of the gel may influence the nucleation barrier $^{174)}$.

Zarzycki ${ }^{174)}$ points out that both the sintering and crystallization rates depend on the ratio of heat treatment time to viscosity, $t / \eta$. Therefore,

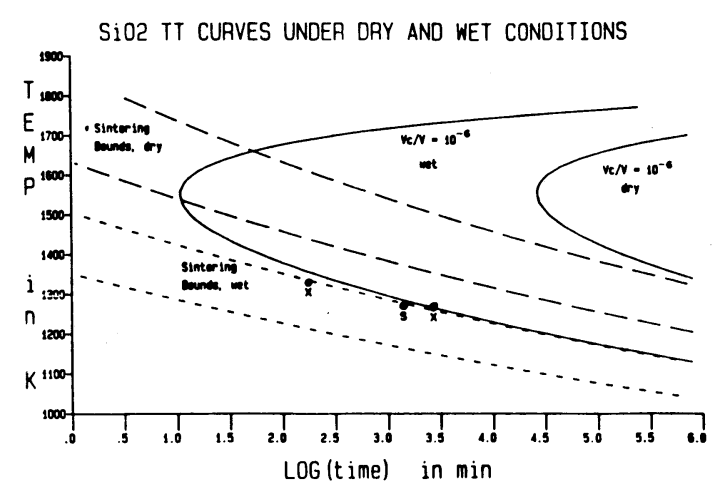

Fig. 25. $\mathrm{SiO}_{2}$ sintering (dashed) and crystallization (solid) curves under dry and "wet" conditions. The lower viscosity observed by Sacks and Tseng ${ }^{173)}$ shifts all curves to shorter times at any temperature. Their data for sol-gel glasses also included : X marks treatments which resulted in crystallization with little sintering and $\mathrm{S}$ marks treatments which produced sintered glasses free of crystallinity (from Uhlmann et al. $\left.^{60)}\right)$. Copyright ${ }^{\complement} 1986$ by John Wiley \& Sons, Inc. Reprinted by permission of the publisher. 
the amount of crystallization produced by the time sintering is complete is independent of the thermal history. That is, one cannot reduce the amount of devitrification by changing the heating schedule. This argument applies even though $\eta$ is a function of time as well as temperature, since both processes still depend on $\int \mathrm{d} t / \eta$. However, Zhu et al. ${ }^{175)}$ showed that the outcome can be affected by the method of preparation of the gel, since the sintering rate is influenced by the microstructure of the gel. The smaller pores of an acid-catalyzed gel promote rapid sintering, so a gel of a given composition is less likely to crystallize during densification.

\section{Comparison of properties}

It is clear that the properties of a gel are different from those of a melted glass of the same composition. In addition to the porosity, the gel has a large fraction of nonbridging bonds, so that the thermal expansion coefficient is high ${ }^{126}$ and the elastic modulus is $l_{0 w^{142}}$. The structure on an atomic scale is so far from equilibrium that substantial rearrangement can occur well below the glass transition temperature, $T_{\mathbf{g}}{ }^{140)}$. The sintered glass made from a gel may also differ from a conventional glass in the degree of phase separation $^{160)}$ or crystallization ${ }^{176)}$. This is not surprising, since these processes involve diffusion over distances on the order of 1 to $10 \mathrm{~nm}$. Since gels can be sintered near $T_{\mathrm{g}}$, densification may be complete before diffusion on that scale can occur.

Properties that depend on the local atomic arrangement approach equilibrium in a matter of minutes near $T_{\mathrm{g}}$. Consequently, gel-derived and melted glasses show no differences in density, modulus, and thermal expansion coefficient ${ }^{177)}$. It is quite remarkable, therefore that differences have been reported in such properties as liquidus temperature ${ }^{178)}$ and melt viscosity ${ }^{74}$. Scherer et al. ${ }^{179)}$ used the DSC to examine the relaxation kinetics of gels sintered near $T_{\mathrm{g}}$; melted glasses were prepared for comparison. Large differences were found, but were traced to differences in composition. When those differences were eliminated, the properties of the melted glass were indistinguishable from those of a gel sintered near $T_{\mathrm{g}}$.

The structural relaxation time, $\tau_{\mathrm{R}}$, is proportional to the viscosity ${ }^{180)}$, so if $\tau_{\mathrm{R}} \approx 100$ seconds at $T_{\mathrm{g}}$ (where $\eta \approx 10^{12} \mathrm{~Pa} \cdot \mathrm{s}$ ), then $\tau_{\mathrm{R}} \approx 100$ micro- seconds at the liquidus temperature $\left(\eta \approx 10^{6} \mathrm{~Pa} \cdot \mathrm{s}\right)$. Therefore, differences in high-temperature properties must reflect differences in composition between the gel-derived and melted glasses, despite statements to the contrary ${ }^{74}$. In fact, Weinberg and Neilson ${ }^{181)}$ report that their earlier compositional analyses were mistaken; no differences in high temperature properties are found when the compositions of the glasses are identical.

\section{Conclusions}

It is clear that a scientific foundation is being built on which the sol-gel technology can grow. Opportunities exist to improve every stage of the process, and rapid progress is being made. Many applications have appeared and more are to be expected, especially in materials for very high temperatures (e.g. refractory glass-ceramics) and low temperatures (organically modified gels).

Acknowledgment I am pleased to acknowledge my debt to Jeff Brinker, with whom I have been privileged to collaborate in this field since 1980. I also thank my collaborators at DuPont for permission to cite their results in advance of publication.

\section{References}

1) W. Geffcken and E. Berger, Dtsch. Reichspatent 736411 (1939) Jenaer Glaswerk Schott und Gen., Jena, GDR.

2) H. Schroeder, Phys. Thin Films, 5, 87-141 (1969).

3) H. Dislich, Angew. Chem. Int. Ed., 10, 363-70 (1971).

4) R. Roy, J. Am. Ceram. Soc., 39, 145-46 (1956).

5) R. Roy, J. Am. Ceram. Soc., 52, 344 (1969).

6) H. Dislich, Glastech. Ber., 44, 1-7 (1971).

7) R. D. Shoup, Colloid and Interface Sci., VII, 63-69 (1976).

8) B. E. Yoldas, Am. Ceram. Soc. Bull., 54, 286-90 (1975).

9) B. E. Yoldas, J. Mater. Sci., 12, 1203-08 (1977).

10) M. Yamane, S. Aso and T. Sakaino, J. Mater. Sci., 13, 865-70 (1978).

11) M. Yamane, S. Aso, S. Okano and T. Sakaino, J. Mater. Sci., 14, 607-11 (1979).

12) M. Nogami and Y. Moriya, Yogyo-Kyokai-Shi, 87, 37-42 (1979).

13) E. M. Rabinovich, D. W. Johnson, Jr., J. B. MacChes ney and E. M. Vogel, J. Am. Ceram. Soc., 66, 683-88 (1983).

14) G. W. Scherer and J.C. Luong, J. Non-Crystalline Solids, 63, 163-72 (1984).

15) D. L. Segal, J. Non-Crystalline Solids, 63, 183-91 (1984).

16) J. D. Mackenzie, p. 15-26 in "Ultrastructure Processing of Ceramics, Glasses, and Composites", eds. L. L. Hench and D. R. Ulrich, John Wiley \& Sons, NY (1984).

17) D. R. Uhlmann, B. J. J. Zelinski and G.E. Wnek, p. 59-70 in "Better Ceramics Through Chemistry", eds. C. J. Brinker, D.E. Clark and D.R. Ulrich, NorthHolland, NY (1984).

18) S. Sakka and K. Kamiya, J. Non-Crystalline Solids, 42, 403-22 (1980)

19) A. Sen and D. Chakravorty, Proc. Indian Natl. Acad, 52 A, 159-75 (1986).

20) E. M. Rabinovich, J. Mater. Sci., 20, 4259-97 (1985).

21) Proc. Int. Workshop on Glasses and Glass Ceramics 
from Gels, J. Non-Crystalline Solids, 48 [1] (1982).

22) Proc. Second Int. Workshop on Glasses and Glass Ceramics from Gels, J. Non-Crystalline Solids, 63 [1-2] (1984).

23) Proc. Third Int. Workshop on Glasses and Glass Ceramics from Gels, J. Non-Crystalline Solids, 82 [1-3] (1986).

24) "Better Ceramics Through Chemistry", eds. C. J. Brinker, D. E. Clark and D.R. Ulrich, North-Holland, NY (1984).

25) Proc. Materials Research Soc. Symp. on "Better Ceramics Through Chemistry", Palo Alto, CA, April (1986) in press.

26) "Ultrastructure Processing of Ceramics, Glasses, and Composites", eds. L. L. Hench and D. R. Ulrich, John Wiley \& Sons, NY (1984).

27) "Science of Ceramic Chemical Processing", eds. L. L. Hench and D. R. Ulrich, John Wiley \& Sons, NY (1986).

28) D. C. Bradley, R. C. Mehrotra and D. P. Gaur, "Metal Alkoxides“, Academic Press (1978).

29) K. A. Andrianov, "Organic Silicon Compounds". State Scientific Publishing House for Chemical Literature, Moscow (1955), translation 59-11239 U.S. Dept. of Commerce, Washington, D. C., USA.

30) G. J. McCarthy and R. Roy, J. Am. Ceram. Soc., 54, 639 (1971)

31) L. Levene and I. M. Thomas, U.S. Pat. 3,640,093 (1972).

32) J. D. Mackenzie, p. 113-22 in "Ultrastructure Processing of Ceramics, Glasses, and Composites", eds. L. L. Hench and D. R. Ulrich, John Wiley \& Sons, NY (1984).

33) K. C. Chen, T. Tsuchiya, and J. D. Mackenzie, J. Non-Crystalline Solids, 81, 227-37 (1986).

34) M. Yamane, S. Inoue and K. Nakazawa, J. NonCrystalline Solids, 48, 153-59 (1982).

35) L. W. Kelts, N. J. Effinger and S. M. Melpolder, J. Non-Crystalline Solids, 83, 353-74 (1986).

36) C. J. Brinker, K. D. Keefer, D. W. Schaefer, R. A. Assink, B. D. Kay and C. S. Ashley, J. Non-Crystalline Solids, 63, 45-59 (1984).

37) K. A. Andrianov and A. A. Zhdanov, J. Polym. Sci., 30, 513-24 (1958).

38) J.S. Smith II, R. T. Dolloff and K. S. Mazdiyasni, J. Am. Ceram. Soc., 53, 91-95 (1970)

39) R. E. Riman, D. M. Haaland, C. J. M. Northrup, Jr., H. K. Bowen and A. Bleier, p. 233-38 in "Better Ceramics Through Chemistry”, eds. C.J. Brinker, D.E. Clark and D. R. Ulrich, North-Holland, NY (1984).

40) B. J. J. Zelinsky, B. D. Fabes and D. R. Uhlmann, J. Non-Crystalline Solids, 82, 307-13 (1986).

41) P.E. D. Morgan, H. A. Bump, E. A. Pugar and J. J. Ratto, p. 327-334 in "Science of Ceramic Chemical Processing”, eds. L. L. Hench and D. R. Ulrich, John Wiley \& Sons, NY (1986).

42) H. Schmidt and H. Scholze, NATO ASI Ser., E92 (Glass) 263-80 (1985).

43) C. J. Brinker and S. T. Reed, U. S. Pat. 4, 476, 156, Oct. 9, 1984, assigned to U.S. Dept. of Energy.

44) P. Hinz and H. Dislich, J. Non-Crystalline Solids, 82, 411-16 (1986).

45) Suwa Seikosha Co., Ltd., Japan, Jap. Pat. Appl. 83/160748, Sept. (1983).

46) H. Schmidt, J. Non-Crystalline Solids, 73, 681-91 (1985).

47) G. Philipp and H. Schmidt, J. Non-Crystalline Solids, 63, 283-92 (1984).

48) A. Kaiser, H. Schmidt and H. Bottner, J. Membrane Sci., 22, 257-68 (1985).

49) H. Schmldt, H. Scholze and G. Tunker, J. NonCrystalline Solids, 80, 557-63 (1986).
50) D. Ravaine, A. Seminel, Y. Charbouillot and M. Vincens, J. Non-Crystalline Solids, 82, 210-19 (1986).

51) G. L. Wilkes, B. Orler and H. Huang, Polym. Prepr., 26, 300-02 (1985).

52) H. Huang, B. Orler and G. L. Wilkes, Polymer Bulletin, 14, 557-64 (1985).

53) R.K. Iler, "The Chemistry of Silica”, John Wiley \& Sons, NY (1979)

54) H. Schmidt, H. Scholze and A. Kaiser, J. NonCrystalline Solids, 63, 1-11 (1984).

55) K. K. Keefer, p. 15-24 in "Better Ceramics Through Chemistry", eds. C. J. Brinker, D. E. Clark and D. R. Ulrich, North-Holland, NY (1984).

56) R. Aelion, A. Loebel and F. Eirich, J. Am. Chem. Soc., 72, 5705-12 (1950).

57) I. G. Khaskin, Dokl. Akad. Nauk SSSR, 85, 129 (1952).

58) W. C. LaCourse, M. Ahktar, S. Dahar, R. D. Sand and J. Steinmetz, J. Can. Ceram. Soc., 52, 18-23 (1983).

59) H. Schmidt, A. Kaiser, M. Rudolph and A. Lentz, p. 87-93 in "Science of Ceramic Chemical Processing", eds. L. L. Hench and D. R. Ulrich, John Wiley \& Sons, NY (1986)

60) D. R. Uhlmann, B. J. Zelinski, L. Silverman, S. B. Warner, B.D. Fabes and W.F. Doyle, p. 173-83 in "Science of Ceramic Chemical Processing", eds. L. L. Hench and D. R. Ulrich, John Wiley \& Sons, NY (1986).

61) K. D. Keefer and D. W. Schaefer, Phys. Rev. Lett., 56, 2376-79 (1986).

62) K. D. Keefer, p. 131-39 in "Science of Ceramic Chemical Processing“, eds. L. L. Hench and D. R. Ulrich, John Wiley \& Sons, NY (1986).

63) R.A. Assink and B.D. Kay, p.301-06 in “Better Ceramics Through Chemistry", eds. C. J. Brinker, D.E. Clark and D.R. Ulrich, North-Holland, NY (1984).

64) D.W. Schaefer and K.D. Keefer, p. 1-14 in "Better Ceramics Through Chemistry", eds. C. J. Brinker, D.E. Clark and D.R. Ulrich, North-Holland, NY (1984).

65) C.J. Brinker and G.W. Scherer, J. Non-Crystalline Solids, 70, 301-22 (1985).

66) I. Strawbridge, A.F. Craievich and P.F. James, J. Non-Crystalline Solids, 72, 139-57 (1985).

67) G. C. Ruben and M.W. Shafer, p. 448-49 in Proc. 44 th Ann. Mtg. Electron Microscopy Soc. of Amer., San Francisco Press, Inc., San Francisco, CA, USA (1986).

68) S. Sakka, K. Kamiya, K. Makita and Y. Yamamoto, $J$ Non-Crystalline Solids, 63, 223-35 (1984).

69) A. Dauger, F. Chaput, J. C. Pouxviel and J. F. Boilot, $J$. de Physique, C 8, 455-59 (1985).

70) W. Stober, A. Fink and E. Bohn, J. Colloid and Interface Sci., 26, 62-69 (1968).

71) S. Sakka and K. Kamiya, J. Non-Crystalline Solids, 48, 31-46 (1982)

72) F. Orgaz and H. Rawson, J. Non-Crystalline Solids, 82, 57-68 (1986)

73) M. F. Bechtold, R. D. Vest and L. Plambeck, Jr., J. Am. Chem. Soc., 90, 4590-98 (1968).

74) B.E. Yoldas, J. Non-Crystalline Solids, 51, 105-21 (1982).

75) J. Zarzycki, p. 21-36 in "Science of Ceramic Chemical Processing", eds. L. L. Hench and D. R. Ulrich, John Wiley \& Sons, NY (1986).

76) B.E. Yoldas, J. Non-Crystalline Solids, 83, 375-90 (1986).

77) M. Yamane and S. Okano, Yogyo-Kyokai-Shi, 87, 434-38 (1979).

78) R. Puyane, P.F. James and H. Rawson, J. Non- 
Crystalline Solids, 41, 105-15 (1980).

$79)$ B.E. Yoldas, J. Non-Crystalline Solids, 63, 145-54 (1984).

80) S. Sakka, Y. Tanaka and T. Kokubo, J. Non-Crystalline Solids, 82, 24-30 (1986).

81) J.D. Mackenzie, p. 113-22 in "Science of Ceramic Chemical Processing", eds. L.L. Hench and D.R. Ulrich, John Wiley \& Sons, NY (1986).

82) V. Gottardi, M. Guglielmi, A. Bertoluzza, C. Fagnano and M. A. Morelli, J. Non-Crystalline Solids, 63, 71-80 (1984).

83) J. C. Debsikdar, Advanced Ceramic Mater., 1 [1] 93-98 (1986).

84) C. J. Brinker and S. P. Mukherjee, J. Mater. Sci., 16 , 1980-88 (1981)

85) L.C. Klein and G.J. Garvey, p. 33-39 in "Better Ceramics Through Chemistry", eds. C.J. Brinker, D.E. Clark and D.R. Ulrich, North-Holland, NY (1984)

86) M. Nogami and Y. Moriya, J. Non-Crystalline Solids, 37, 191-201 (1980).

87) C. J. Brinker, K. D. Keefer, D.W. Schaefer and C.S Ashley, J. Non-Crystalline Solids, 48, 47-64 (1982).

88) M.W. Colby, A. Osaka and J.D. Mackenzie, J. Non-Crystalline Solids, 82, 37-41 (1986).

89) L. L. Hench, p. 52-64 in "Science of Ceramic Chemical Processing“, eds. L. L. Hench and D. R. Ulrich, John Wiley \& Sons, NY (1986).

90) S. Wallace and L. L. Hench, p. 47-52 in "Better Ceramics Through Chemistry”, eds. C. J. Brinker, D. E. Clark and D. R. Ulrich, North-Holland, NY (1984).

91) S.H. Wang and L.L. Hench, p.71-77 in "Better Ceramics Through Chemistry”, eds. C.J. Brinker, D.E. Clark and D.R. Ulrich, North-Holland, NY (1984).

92) L. L. Hench and G. Orcel, J. Non-Crystalline Solids, 82, 1-10 (1986)

93) G. Orcel and L. L. Hench, J. Non-Crystalline Solids, 79, 177-94 (1986).

94) I. Artaki, T. W. Zerda and J. Jonas, Mater. Lett., 3, 493-96 (1985).

95) I. Artaki, M. Bradley, T.W. Zerda, J. Jonas, G. Orcel and L. L. Hench, p. 73-80 in "Seience of Ceramic Chemical Processing”, eds. L. L. Hench and D. R. Ulrich, John Wiley \& Sons, NY (1986).

96) P.J. Flory, "Principles of Polymer Chemistry", Cornell Univ. Press, Ithaca, NY (1953).

97) R. B. Flippen and G.W. Scherer, unpublished work.

98) T. Tanaka, L. O. Hocker and G. B. Benedek, J. Chem. Phys., 59, 5151-59 (1973).

99) P.G. de Gennes, "Scaling Concepts in Polymer Physics", Cornell Univ. Press, Ithaca, NY (1979).

100) R. Zallen, "The Physics of Amorphous Solids", Wiley, NY (1983).

101) M. Sacks and R. Sheu, p. 100-07 in "Science of Ceramic Chemical Processing”, eds. L. L. Hench and D. R. Ulrich, John Wiley \& Sons, NY (1986).

102) L. C. Klein and G. J. Garvey, J. Non-Crystalline Solids, 48, 97-104 (1982).

103) A. J. Vega and G.W. Scherer, unpublished work.

104) M.F. Bechtold, W. Mahler and R. A. Schunn, J. Polym. Sci. : Polym. Chem. Ed., 18, 2823-55 (1980).

105) C. B. Hurd, Chem. Revs., 22, 403-22 (1938).

106) T. W. Zerda, I. Artaki and J. Jonas, J. Non-Crystalline Solids, 81, 365-79 (1986).

107) J. Dumas, J.F. Quinson, C. Bovier, S. Baza and J. Serughetti, J. Non-Crystalline Solids, 82, 220-24 (1986).

108) G.W. Scherer and R. M. Swiatek, unpublished work.

109) T. Kawaguchi, H. Hishikura, J. Iura and Y. Kokubu,
J. Non-Crystalline Solids, 63, 61-69 (1984).

110) D.P. Partlow and B.E. Yoldas, J. Non-Crystalline Solids, 46, 153-61 (1981).

111) M. Prassas, J. Phalippou, L. L. Hench and J. Zarzycki, J. Non-Crystlalline Solids, 48, 79-95 (1982).

112) M. Brun, A. Lallemand, J.F. Quinson and C. Eyraud, Thermochimica Acta, 21, 59-88 (1977).

113) J. F. Quinson, J. Dumas, and J. Serughetti, J. NonCrystalline Solids, 79, 397-404 (1986).

114) J. Zarzycki, M. Prassas, and J. Phalippou, J. Mater. Sci., 17, 3371-79 (1982).

115) J. Zarzycki, p. 27-42 in "Ultrastructure Processing of Ceramics, Glasses, and Composites”, eds. L. L. Hench and D. R. Ulrich, John Wiley \& Sons, NY (1984).

116) A. R. Cooper, p. 261-76 in "Ceramics Processing Before Firing”, John Wiley \& Sons, NY, USA (1978).

117) R. Q. Packard, J. Am. Ceram. Soc., 50, 223-29 (1967).

118) H. H. Macey, Trans. Brit. Ceram. Soc., 41, 73-121 (1942).

119) D. E. Smiles, Soil Science, 117, 140-47 (1974).

120) T. Tanaka and D. J. Fillmore, J. Chem. Phys., 70, 1214-18 (1979).

121) S. Modugno and J.W. Fleming, AT\&T Bell Labs, Murray Hill, to be publishéd.

122) G. W. Scherer, "Drying Gels : I. General Theory; II Film and Flat Plate; III. Warping Plate; IV. Cylinder and Sphere; V. Rigid Gels", to be published in $J$. Non-Crystalline Solids

123) H. S. Carslaw and J. C. Jaeger, "Conduction of Heat in Solids”, Clarendon Press, Oxford (1959).

124) J. Crank, "The Mathematics of Diffusion", Clarendon Press, Oxford (1975).

125) R. K. Dwivedi, J. Mater. Sci. , 5, 373-76 (1986).

126) T. Kawaguchi, J. Iura, N. Taneda, H. Hishikura and Y. Kokubu, J. Non-Crystalline Solids, 82, 50-56 (1986).

127) G. W. Scherer, J. Am. Ceram. Soc., 69, 473-80 (1986).

128) T. Shaw, in Proc. Materials Research Soc. Symp. on "Better Ceramics Through Chemistry", Palo Alto, CA, April (1986) in press.

129) S.S. Kistler, Nature, 127, 741 (1931).

130) S. S. Kistler, J. Phys. Chem., 36, 52-64 (1932).

131) S. J. Teichner et al., Adv. Colloid and Interface Sci. , 5, 245-73 (1976).

132) Springer Proceedings in Physics, Vol.6: “Aerogels”, ed. J. Fricke, Springer-Verlag, Berlin, FRG (1986).

133) S. Henning and L. Svensson, Physica Scripta, 23, 697-702 (1981)

134) J.G. van Lierop, A. Huizing, W. C. P. M. Meerman and C.A.M. Mulder, J. Non-Crystalline Solids, 82, 265-70 (1986).

135) P.H. Tewari, A. J. Hunt, and K.D. Lofftus, Mater. Lett. , 3 [9, 10] 363-67 (1985).

136) C. A. M. Mulder, G. van Leeuwen-Stienstra, J. G. van Lierop and J.P. Woerdman, J. Non-Crystlalline Solids, 82, 148-53 (1986).

137) D. W. Schaefer, K. D. Keefer, J. H. Aubert and P. B Rand, p. 140-47 in "Science of Ceramic Chemical Processing", eds. L. L. Hench and D. R. Ulrich, John Wiley \& Sons, NY (1986)

138) S. Lowell and J. E. Shields, "Powder Surface Area and Porosity", 2d ed., Chapman and Hall, NY (1984).

139) S. Wallace and L. L. Hench, p. 148-55 in "Science of Ceramic Chemical Processing", eds. L. L. Hench and D. R. Ulrich, John Wiley \& Sons, NY (1986).

140) C.J. Brinker and G.W. Scherer, p. 43-59 in "Ultrastructure Processing of Ceramics, Glasses, and Composites", eds. L. L. Hench and D. R. Ulrich, John Wiley \& Sons, NY (1984).

141) J. Wenzel, J. Mater. Sci., 17, 3380-82 (1982). 
142) M. J. Murtagh, E. K. Graham and C. G. Pantano, to be published in J.Am. Ceram. Soc.

143) G. Carturan, V. Gottardi and M. Graziani, J. NonCrystalline Solids, 29, 41-48 (1978).

144) C. J. Brinker, E.P. Roth, G. W. Scherer and D. R. Tallant, J. Non-Crystalline Solids, 71, 171-85 (1985).

145) B. E. Yoldas, J. Mater. Sci., 14, 1843-49 (1979).

146) K. Susa, I. Matsuyama, S. Satoh and T. Suganuma, Electronic Lett., 18, 499-500 (1982).

147) K. Susa, I. Matsuyama, S. Satoh and T. Suganuma, J. Non-Crystalline Solids, 79, 165-76 (1986).

148) E. M. Rabinovich, D. L. Wood, D. W. Johnson, Jr., D. A. Fleming, S. M. Vincent and J. B. MacChesney, J. Non-Crystalline Solids, 82, 42-49 (1986).

149) J. Phalippou, T. Woignier and J. Zarzycki, p. 70-87 in "Ultrastructure Processing of Ceramics, Glasses, and Composites", eds. L. L. Hench and D. R. Ulrich, John Wiley \& Sons, NY (1984).

150) C. J. Brinker, G.W. Scherer and E.P. Roth, J. Non-Crystalline Solids, 72, 345-68 (1985).

151) C.J. Brinker, W.D. Drotning and G.W. Scherer, p. 25-32 in "Better Ceramics Through Chemistry", eds. C. J. Brinker, D.E. Clark and D.R. Ulrich, NorthHolland, NY (1984).

152) D. M. Krol and J.G. van Lierop, J. Non-Crystalline Solids, 63, 131-44 (1984).

153) C. J. Brinker, D. R. Tallant, E. P. Roth and C.S. Ashley, p. 387-411 in "Defects in Glasses", eds. F. L. Galeener, D. L. Griscom and M. J. Weber, Materials Research Society, Vol.61, North-Holland, NY (1986).

154) G. W. Scherer, C. J. Brinker and E.P. Roth, J. Non-Crystalline Solids, 72, 369-89 (1985).

155) G. W. Scherer, to be published in "Surface and Colloid Science”, Vol.14, ed. E. Matijevic, Plenum Publ. Corp., NY.

156) J. Frenkel, J. Phys. (Moscow), 9, 385-91 (1945).

157) J. K. Mackenzie and R. Shuttleworth, Proc. Phys. Soc., London, 62, 838-52 (1949).

158) G.W. Scherer, J. Am. Ceram. Soc., 60, 236-39 (1977).

159) G.W. Scherer, J. Am. Ceram. Soc., 67, 709-15 (1984).

160) M. Yamane and T. Kojima, J. Non-Crystalline Solids, 44, 181-90 (1981).

161) T. A. Gallo and L.C. Klein, in Proc. Materials Research Soc. Symp. on "Better Ceramics Through Chemistry", Palo Alto, CA, April (1986) in press.

162) T.A. Gallo, C.J. Brinker, L.C. Klein and G. W. Scherer, p. 85-90 in "Better Ceramics Through Chemistry”, eds. C. J. Brinker, D. E. Clark, and D. R. Ulrich, North-Holland, NY (1984).

163) T. A. Gallo and L. C. Klein, J. Non-Crystalline Solids, 82, 198-204 (1986).

164) L. C. Klein, T. A. Gallo and G. J. Garvey, J. NonCrystalline Solids, 63, 23-33 (1984).

165) T. Woignier, J. Phalippou and J. Zarzycki, J. Non-
Crystalline Solids, 63, 117-30 (1984).

166) P. I. K. Onorato, to be published in J. Am. Ceram. Soc.

167) C. A. M. Mulder, J. G. van Lierop and G. Frens, J. Non-Crystalline Solids, 82, 92-96 (1986).

168) A. Yasumori, S. Inoue and M. Yamane, J. NonCrystalline Solids, 82, 177-82 (1986).

169) M. Decottignies, J. Phalippou and J. Zarzycki, J. Mater. Sci., 13, 2605-18 (1978).

170) I. Schwartz, P. Anderson, H. de Lambilly and L.C. Klein, J. Non-Crystalline Solids, 83, 391-99 (1986).

171) S.P. Mukherjee, J. Non-Crystalline Solids, 82, 293-300 (1986).

172) D. R. Uhlmann, J. Non-Crystalline, Solids, 7, 337-48 (1972).

173) M. D. Sacks and T.Y. Tseng, J. Am. Ceram. Soc., 69, 532-37 (1984).

174) J. Zarzycki, p. 204-17 in Advances in Ceramics, Vol.4, "Nucleation and Crystallization in Glasses", eds. J. H. Simmons, D. R. Uhlmann and G. H. Beall, Am. Ceram. Soc., Columbus, OH, USA (1982).

175) C. Zhu, J. Phalippou and J. Zarzycki, J. NonCrystalline Solids, 82, 321-28 (1986).

176) G. F. Neilson and M.C. Weinberg, J. Non-Crystalline Solids, 63, 365-74 (1984).

177) J.D. Mackenzie, J. Non-Crystalline Solids, 48, 1-10 (1982).

178) M. C. Weinberg and G.F. Neilson, J. Am. Ceram. Soc., 66, 132-34 (1983).

179) G. W. Scherer, C. J. Brinker and E.P. Roth, J. Non-Crystalline Solids, 82, 191-97 (1986).

180) G.W. Scherer, "Relaxation in Glass and Composites", John Wiley \& Sons, NY (1986).

181) M. C. Weinberg and G.F. Neilson, to be published.

182) M. Prassas and L.L. Hench, p. 100-25 in "Ultrastructure Processing of Ceramics, Glasses and Composites", eds. L. L. Hench and D. R. Ulrich, John Wiley \& Sons, NY (1984).

\section{Biography}

Dr. George Scherer received his $\mathrm{PhD}$ from MIT and joined Corning Glass Works in 1974. He worked on fabrication of optical waveguides, including studies of sintering kinetics and stress optical effects, then developed a colloidal gel process for the production of optical quality glass. Recently he has published a book, "Relaxation in Glass and Composites", that was begun while teaching a course on the subject at MIT as a Visiting Professor. He is currently working in the Central Research Dept. at DuPont, studying the drying mechanics of gels made from alkoxides. Last year he won the George W. Morey and Ross Coffin Purdy Awards from the American Ceramic Society, and the Woldemar Weyl Award from the International Commission on Glass. He holds 7 patents and is the author of about 60 papers. 